PALBRAS CLAVE

Infraestructura física

Financiación

Inversiones

Sector público

Sector privado

Instituciones financieras

Datos estadísticos

Análisis comparativo

América Latina

Asia

Patricio Rozas

Funcionario de la División de Recursos

Naturales e Infraestructura, CEPAL

œ patricio.rozas@cepal.org
REVISTA CEPAL $101 \bullet A G O S T O 2010$

\section{América Latina: problemas y desafíos del financiamiento de la infraestructura}

\author{
Patricio Rozas
}

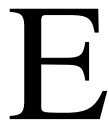

objetivo de este artículo es cuantificar la evolución de las diversas áreas de la infraestructura básica en los países de la región y precisar la dimensión del atraso que estas registran con respecto a los países del sudeste de Asia, cuyo nivel de desarrollo era claramente inferior al de los países latinoamericanos a fines de los años setenta del siglo pasado. En particular, interesa precisar las principales características - a modo de tendencias generales- del desarrollo de la infraestructura básica en América Latina, con especial énfasis en los problemas que registra el proceso inversor en el sector, a fin de establecer las principales consecuencias que tales problemas conllevan y especificar, de este modo, los desafíos que los países de la región están llamados a enfrentar. 


\section{I \\ Desarrollo de la infraestructura básica en América Latina}

En diversos trabajos empíricos se ha examinado la relación entre la inversión en infraestructura y el crecimiento económico, encontrando una correlación positiva y significativa, sin que ello denote necesariamente una dirección de causalidad entre ambas variables (Rozas y Sánchez, 2004). La dinámica que sustenta esta relación es relativamente transparente: una mayor disponibilidad y calidad de los servicios de infraestructura —medidas en términos de telecomunicaciones; red vial y servicios de transporte; generación, transmisión y distribución de energía; y abastecimiento de agua potable y servicios de saneamiento- implican para los productores una mayor productividad de los factores y costos de producción más bajos. La mayor rentabilidad incentiva la inversión y, por ende, aumenta el crecimiento potencial del producto. En estudios recientes se señala que las deficiencias en las redes de carretera y telecomunicaciones elevan significativamente los costos de transporte $\mathrm{y}$, en general, los costos logísticos, que sobrepasan los estándares internacionales afectando la competitividad de las empresas, las industrias y las economías en su conjunto (Guasch y Kogan, 2001; CEPAL, 2004).

En la década de 1990, la industria latinoamericana de servicios de infraestructura registró una acentuada transformación estructural, que se extendió por las telecomunicaciones, la energía, los servicios sanitarios y el transporte. En la mayoría de los países de la región se puso término a los monopolios estatales y se estimuló la participación de agentes privados en mercados que hasta entonces habían estado reservados a empresas fiscales, derogándose las barreras legales para la entrada en algunos segmentos de la industria.

La redefinición del papel del Estado en la provisión de servicios de infraestructura significó que en la mayoría de los países de la región se procediera a privatizar las empresas estatales de cada sector — muchas de ellas monopolios protegidos legalmente- y se pusieran en práctica marcos institucionales y legales de regulación. En numerosos casos, esta situación devino en la creación

$\square$ El autor agradece la asistencia de Mauro Gutiérrez, que ayudó en la compilación y procesamiento de la información estadística. de agencias reguladoras de las actividades emprendidas por las empresas privadas en cada sector.

La apertura de los mercados de servicios de infraestructura y la venta de las empresas estatales permitieron el ingreso de empresas extranjeras portadoras en muchos casos de nuevas técnicas de producción, tecnologías y modalidades de organización empresarial, que resultaron determinantes para la modernización de la infraestructura y de los servicios producidos localmente. Por cierto, esta modernización resulta crucial para obtener mayores ganancias de competitividad sistémica y atraer nuevas corrientes de inversión a los demás sectores productivos.

A pesar de la amplitud de estas tendencias, las reestructuraciones de los servicios dieron origen a una diversidad de modelos que difieren no solo de un sector a otro, sino también de un país a otro para un mismo sector. Esta diversidad obedece a marcadas diferencias derivadas del tamaño y estructura de los mercados, del grado real de competencia que es posible introducir en cada país y en cada servicio, de los procesos de formación de los precios, de la cobertura y calidad de los servicios, e incluso de sus impactos ambientales.

De esta manera, entre 1985 y 2007, en la mayoría de los países de América Latina mejoró la cobertura y calidad de los servicios relacionados con la disponibilidad de infraestructura física y de redes. En los últimos 10 años la expansión ha sido espectacular en el mercado de teléfonos celulares e Internet, alcanzando uno de los mayores índices de desarrollo a nivel mundial (Rozas, 2008a). También ha crecido la cobertura del servicio eléctrico y se han modernizado muchos puertos mediante concesiones (Doerr y Sánchez, 2006). Sin embargo, en el segmento de caminos la cobertura no ha sufrido mayores variaciones (CEPAL, 2004; Fay y Morrison, 2005; Sánchez y Wilmsmeier, 2005).

A pesar de las mejoras, el crecimiento de las coberturas de los servicios provenientes de la infraestructura, que ha permitido mejores condiciones para el desarrollo económico, ha sido insuficiente como se apreciará en las páginas siguientes.

Las deficiencias en infraestructura económica, causadas por problemas de organización industrial de los mercados o por insuficiencias físicas, están dificultando podrían hacerlo en breve — la capacidad de América Latina 
de sostener el crecimiento, aumentar la productividad de los factores y la competitividad de las economías y reducir la pobreza. En la región se debe superar la restricción infraestructural para asegurar condiciones que permitan dar una base de sostenibilidad al crecimiento. Ello explica las necesidades de inversión en el sector.
La diferencia de comportamiento entre la oferta y la demanda de infraestructura está provocando dos efectos principales, de por sí preocupantes: i) un creciente retraso relativo de la región con respecto a otras economías emergentes, y ii) una tendencia a la insuficiencia en la provisión de servicios de infraestructura.

\section{II}

\section{La inversión en infraestructura:} un desafío no resuelto

La principal razón del desarrollo insuficiente de la infraestructura básica de América Latina en las últimas dos décadas radica en las dificultades que han tenido los países para mantener un ritmo adecuado de inversión en las distintas actividades del sector.

El promedio anual de la inversión en infraestructura de las principales economías de América Latina durante los quinquenios 1980-1985, 1996-2001 y 2002-2006 bajó de $3,7 \%$ a $2,2 \%$ y a $1,5 \%$ del producto interno bruto (PIB), respectivamente. Esta es una disminución considerable si se tiene en cuenta que durante el primer quinquenio de los años ochenta la región fue afectada por la crisis de la balanza de pagos y por altos niveles de endeudamiento externo, lo que contrajo drásticamente la demanda agregada y, en consecuencia, la inversión. Esto determinó que el parámetro respecto del cual se compara la inversión promedio de los quinquenios 1996-2001 y 2002-2006 —es decir, el valor promedio del quinquenio 1980-1985 - no fuera muy exigente, porque su magnitud estuvo condicionada por la situación de crisis que afectó a la región en la primera mitad de los años ochenta. A pesar de esta baja exigencia del parámetro, la inversión promedio de los períodos 1996-2001 y 2002-2006 disminuyó considerablemente respecto del valor de referencia.

De acuerdo con la información presentada en el gráfico 1, la declinación de la inversión en infraestructura

GRÁFICO 1

América Latinaa: inversión en áreas de infraestructura como porcentaje del PIB, períodos 1980-1985, 1996-2001, 2002-2006

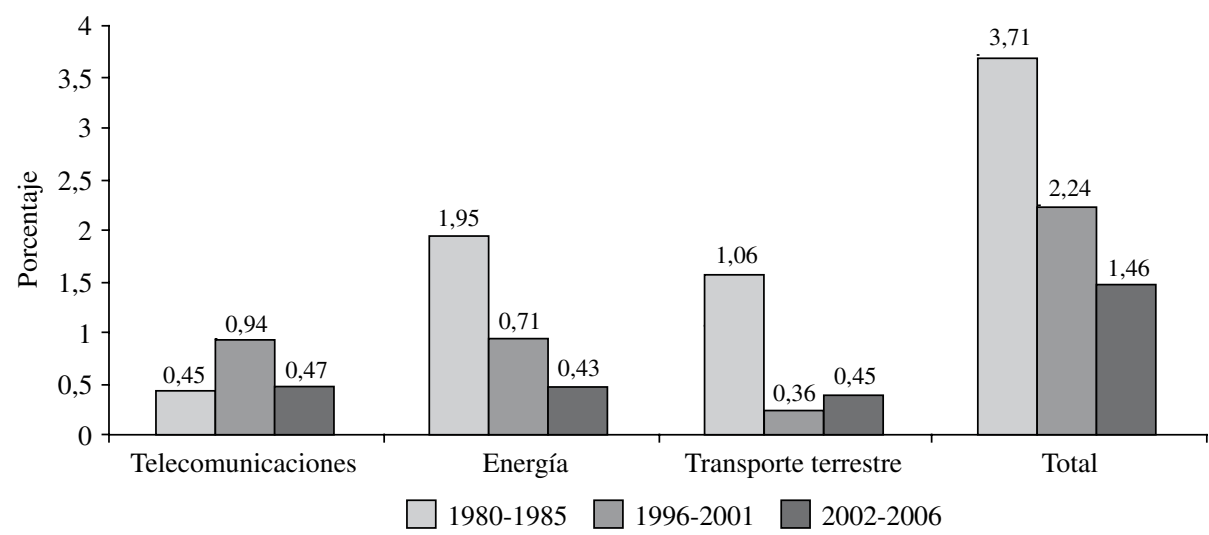

Fuente: períodos 1980-1985 y 1996-2001: César Calderón y Luis Servén, “Trends in infrastructure in Latin America, 1980-2001”, Documento de trabajo, N ${ }^{\circ}$ 269, Santiago de Chile, Banco Central de Chile, septiembre de 2004; período 2002-2006, elaboración propia sobre la base de datos del Banco Mundial y estadísticas nacionales.

a Incluye a la Argentina, el Brasil, Chile, Colombia, el Estado Plurinacional de Bolivia, México y el Perú.

PIB: Producto interno bruto. 
a lo largo del período 1980-2006 fue especialmente notoria en las áreas de energía y transporte terrestre, aunque en esta última se produjo alguna recuperación en el quinquenio 2002-2006 respecto del quinquenio 1996-2001, aumentando de 0,36\% a 0,45\% del PIB de los países incluidos en la muestra investigada. Una evolución distinta registra la inversión en la industria de telecomunicaciones, donde se advierte un ostensible crecimiento en la segunda mitad de la década de 1990 respecto de comienzos de los años ochenta, para disminuir en el quinquenio 2002-2006 a niveles apenas superiores a los iniciales.

En parte importante de la literatura económica más reciente dedicada al tema se ha intentado explicar la declinación de los flujos de inversión hacia el sector, identificándose un conjunto de aspectos que contribuyen a tal contracción. Entre estos elementos se han mencionado la disminución del gasto público, la menor contribución de los organismos multilaterales de crédito y agencias bilaterales y la declinación de los aportes privados. Por cierto, la discusión sobre los problemas que subyacen al comportamiento de los componentes de la inversión agregada en infraestructura es un tema todavía pendiente en la literatura. Hasta ahora prevalecen los análisis sectorializados de los factores que han estado determinando esta situación y en los que se abordan en muy pocos casos las reformas estructurales aplicadas durante la década de 1980 y el primer lustro de los años noventa. Estas debieran constituir el objeto principal del análisis para aprehender la dinámica de los diversos procesos en curso tanto en la industria de infraestructura básica como en la prestación de los servicios conexos.

Una complicación adicional ha derivado del carácter parcial de la información disponible - en algunos casos solo se trata de aproximaciones- y de la tendencia de algunos analistas a extrapolar situaciones que tienden a producirse más intensamente en los países más grandes y de mayor gravitación de la región, validándolas para el resto de los países como parte de tendencias más generales, lo que no necesariamente ocurre de la manera como se enuncia.

En esta perspectiva, el estudio realizado por Calderón y Servén (2004) contribuye a precisar las variadas tendencias que es posible observar en la región, más allá de la evolución de los valores agregados de las variables de inversión. En el estudio mencionado, ambos autores comparan la inversión total de inicios de la década de 1980 con la de los inicios del primer decenio del presente siglo en las principales economías de América Latina (la Argentina, el Brasil, Chile, Colombia, México y el Perú), además del Estado Plurinacional de Bolivia. Los resultados obtenidos permiten ver que en la mayoría de los países se experimenta una importante declinación que solo se revierte escasamente en algunos casos a principios de la década de 1990. Según el estudio citado, la excepción a la tendencia descrita la constituyen Colombia y Chile, países en que se aprecia un importante incremento de la inversión en infraestructura durante dicha década (Calderón y Servén, 2004).

Los datos presentados en el estudio citado denotan, asimismo, que la inversión total en infraestructura cae fuertemente en los países de economías grandes (el Brasil, la Argentina y México), de modo que el gasto anual promedio en infraestructura disminuye a la mitad en el período 1996-2001 con respecto al de 1980-1985, y se eleva en las economías más pequeñas (Chile, Colombia, el Estado Plurinacional de Bolivia y el Perú), y de manera particularmente relevante en Chile y Colombia: $5,6 \%$ y $5,8 \%$, respectivamente. En el período siguiente (2002-2006), la información obtenida deja ver que la declinación de la tasa de inversión en infraestructura se acentúa en todos los países de la muestra, con la excepción de México, e incluso en aquellos países que habían registrado un mejor desempeño durante el período anterior (véase el gráfico 2).

Las preguntas relevantes que cabe formularse se relacionan entonces con esta disparidad: ¿Qué factores determinan que en algunos países la inversión en infraestructura durante la segunda mitad de los años noventa sea más alta que la registrada a comienzos de los años ochenta, en tanto que en otros países cae a la mitad? ¿Por qué la tasa de inversión en infraestructura desciende tan abruptamente en Chile y Colombia, países que presentaban tasas promedio cercanas al $6 \%$ de sus respectivos PIB a fines de los años noventa? ¿Es suficiente una tasa de inversión en infraestructura de $6 \%$ del PIB para enfrentar satisfactoriamente las demandas que emergen de la propia dinámica del crecimiento económico y del desarrollo?

Es posible que algunos analistas procuren subestimar el descenso observado y destaquen tanto el crecimiento del PIB en el período 2004-2007 —muy por encima del promedio de las dos décadas precedentes- como una eventual maduración de los mercados en determinadas áreas de la industria de infraestructura, como los factores causales de tal declinación, validando de esta manera el carácter no lineal de la relación estimada entre infraestructura y crecimiento en el largo plazo (efecto positivo, pero decreciente).

En América Latina, ambos argumentos son discutibles. Primero, porque es erróneo suponer un 


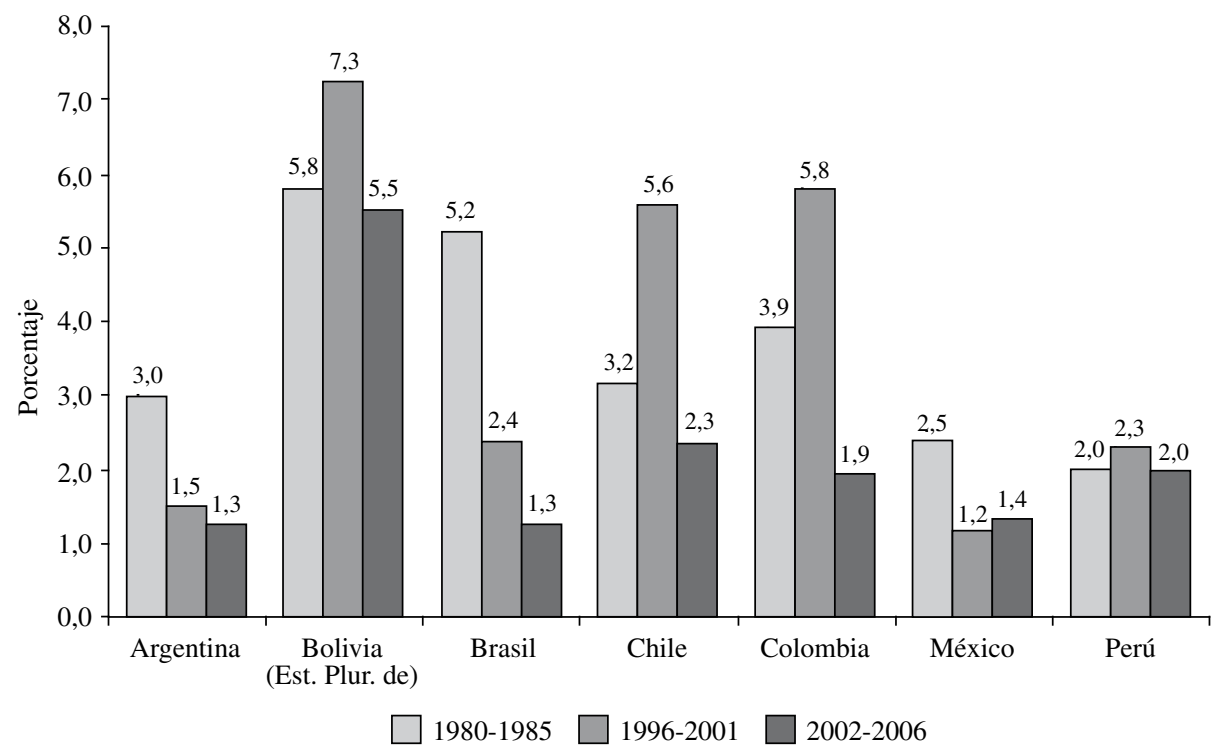

Fuente: períodos 1980-1985 y 1996-2001: César Calderón y Luis Servén, “Trends in infrastructure in Latin America, 1980-2001”, Documento de trabajo, $\mathrm{N}^{\circ}$ 269, Santiago de Chile, Banco Central de Chile, septiembre de 2004; período 2002-2006: elaboración propia sobre la base de datos del Banco Mundial y estadísticas nacionales.

PIB: Producto interno bruto.

comportamiento autónomo de la inversión en infraestructura con relación a la variación del producto, especialmente en aquellos países que arrastran un marcado déficit de infraestructura, desconociéndose la elasticidad producto respecto de la prestación de servicios conexos que han sido medidos en numerosos estudios bajo diferentes circunstancias (Rozas y Sánchez, 2004), y muy especialmente la estrecha causalidad bidireccional que detectaron Canning y Pedroni (1999) entre ambas variables cuando se permite heterogeneidad en las interacciones de corto plazo entre la infraestructura y el PIB.

Y segundo, porque se asigna a los países de la región un horizonte demasiado bajo en cuanto a la maduración de los mercados de servicios de infraestructura, nivel que queda en evidencia al compararse los indicadores de cobertura y de densidad que han alcanzado tales servicios en América Latina respecto de los niveles registrados en los países de mayor desarrollo. En consecuencia, parece más razonable explorar el comportamiento de los principales componentes de la inversión en infraestructura a fin de encontrar los elementos de explicación de esta declinación, lo que se hace necesario para definir los lineamientos generales de política y medidas que se estimen pertinentes.

\section{Inversión pública}

En diferentes estudios se ha encontrado una estrecha correlación entre el aumento de los déficits primarios del sector público y la reducción de los presupuestos de inversión pública en general y de infraestructura, en particular.

El magro desempeño en materia de inversión en infraestructura es el reflejo de las dificultades financieras por las que atravesaron la mayoría de los gobiernos de la región desde la crisis de la deuda externa iniciada en 1982. La necesidad de realizar profundos ajustes fiscales, junto con el servicio de la deuda externa, condujo a los países a reducir significativamente el gasto público, sobre todo en lo que se refiere a inversión.

Existen evidencias suficientes para afirmar que durante los años noventa los ministerios de hacienda y los gobiernos latinoamericanos, enfrentados a situaciones de crisis fiscales, encontraron más sencillo suspender o anular la ejecución de grandes proyectos de infraestructura antes que afectar el pago de la deuda externa, las pensiones o las remuneraciones del sector público.

Por esta razón, entre 1988 y 1998 el gasto público en infraestructura se redujo en América Latina del $3 \%$ al 1,8\% 
del PIB, alejándose del nivel requerido para alcanzar a los denominados "tigres" del Asia (Fay y Morrison, 2005). Los antecedentes más recientes confirman la tendencia a la baja: en el período 2002-2006, el promedio anual de la inversión pública en infraestructura en el mismo grupo de países equivalió apenas al 0,6\% del PIB, lo que implica que en dicho período la inversión pública en el sector representa menos de la quinta parte de lo que fue a comienzos de los años ochenta.

De acuerdo con estos datos, la retracción de la inversión pública fue particularmente acentuada en las áreas de transporte terrestre y de energía. En la primera, la inversión pública cayó de 0,91\% del PIB (promedio anual del período 1980-1985) a 0,16\% (promedio anual del período 1996-2001), lo que se explica por la escasa prioridad asignada en los países más grandes de la región a este tipo de infraestructura en la política fiscal del segundo quinquenio de los noventa. Esta retracción no fue compensada por una mayor inversión privada, que apenas aumentó de $0,15 \%$ a $0,20 \%$ del PIB — como se verá más adelante— lo que determinó que la inversión total en esa área disminuyera notoriamente, como ya se pudo apreciar en el gráfico 1.

Por otra parte, la caída de la inversión pública en el área de energía (del 1,64\% al 0,31\% del PIB) obedece fundamentalmente a la privatización de las empresas eléctricas en la mayor parte de los países de la región, con la excepción de México, lo que significó que el
Estado dejara de ser un actor relevante en esta área de la infraestructura básica. Del mismo modo que en la infraestructura de transporte terrestre, tampoco en el área de energía la inversión privada pudo compensar la disminución de la inversión pública.

En la información más reciente se advierte que la tendencia a la disminución de la inversión pública se acentuó durante el período 2002-2006, tanto en el área de energía eléctrica como de telecomunicaciones - lo que se vincula a la consolidación del proceso de privatizaciones en ambas actividades- pero se revirtió en la de transporte terrestre. Esta última actividad representó más de la mitad de la inversión pública en infraestructura durante el quinquenio 2002-2006.

De esta manera, la disminución de la inversión pública en infraestructura no se explica solo por la causal anotada por Fay y Morrison (2005), quienes relacionaron esta retracción, principalmente, con la crisis fiscal registrada en los países de la región. Además de la repercusión de las privatizaciones — que determinaron que el Estado dejara de participar de manera directa en actividades tales como energía y telecomunicacioneslos presupuestos de inversión pública se redujeron debido a que en los años noventa se tuvo la percepción de que una parte considerable de la infraestructura básica era susceptible de ser financiada y suministrada mediante inversión privada, lo que se tradujo en los correspondientes criterios de política que orientaron el perfil presupuestal

GRÁFICO 3

América Latina ${ }^{a}$ : inversión pública en áreas de infraestructura como porcentaje del PIB, períodos 1980-1985, 1996-2001, 2002-2006

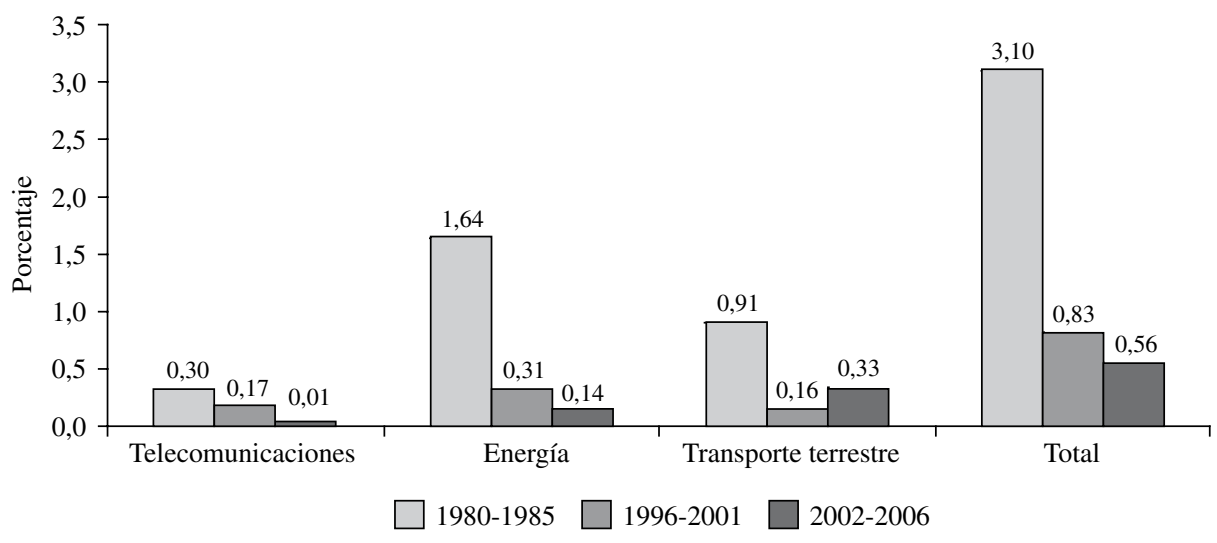

Fuente: períodos 1980-1985 y 1996-2001: César Calderón y Luis Servén, “Trends in infrastructure in Latin America, 1980-2001”, Documento de trabajo, $\mathrm{N}^{\circ} 269$, Santiago de Chile, Banco Central de Chile, septiembre de 2004; período 2002-2006: elaboración propia sobre la base de datos del Banco Mundial y estadísticas nacionales.

a Incluye a la Argentina, el Brasil, Chile, el Estado Plurinacional de Bolivia, Colombia, México y el Perú.

PIB: Producto interno bruto. 
en los períodos que se comparan. En este sentido, buena parte de la discusión se centró en la definición de las condiciones institucionales y normativas más adecuadas para que esta inversión se concretara.

La información relativa a la evolución de la inversión pública en infraestructura en los principales países de la región aporta algunos antecedentes de especial importancia para evaluar los déficits de inversión que se arrastran en el sector. Como se aprecia en el gráfico 4, la caída de la inversión pública durante la segunda mitad de los años noventa es generalizada y se produce en todos los países latinoamericanos de la muestra investigada. Esta reducción es especialmente acentuada en la Argentina, México y el Perú, países donde la inversión pública bajó a guarismos inferiores al 1\% del PIB (promedio anual del período 1996-2001). Asimismo, en el Brasil la inversión pública cayó fuertemente y apenas alcanzó al $1 \%$ del PIB en ese período. A diferencia de los países mencionados, la aminoración es leve en Colombia y algo menos leve en Chile, país en que la inversión siguió teniendo relevancia (1,72\% del PIB). Esta situación se revirtió parcialmente en algunos países durante el quinquenio siguiente, especialmente en la Argentina y México, además del Estado Plurinacional de Bolivia, países donde se incrementa la inversión pública en infraestructura en el marco de la notoria expansión de sus economías, aunque sin alcanzar estas los niveles de comienzos de los años ochenta.
De hecho, a pesar de la recuperación anotada, el promedio anual de la inversión pública en infraestructura durante el período 2002-2006 no superó el 1\% del PIB en ninguno de los países latinoamericanos considerados, con la excepción del Estado Plurinacional de Bolivia y Chile. Por otra parte, al contrario de la Argentina, Estado Plurinacional de Bolivia y México, en los demás países incluidos en la muestra analizada la tendencia a la baja de la inversión pública en infraestructura se mantuvo en el último quinquenio, especialmente en Colombia, uno de los dos países que hasta entonces había mantenido niveles de inversión pública de mayor significancia en el sector. Además, el incremento de esta tendencia fue particularmente notorio en el Brasil y algo menor en el Perú.

Los antecedentes revisados permiten entender de mejor manera la particular situación de países como Chile y Colombia, que registraron tasas de inversión en infraestructura cercanas al 6\% del PIB en el quinquenio 1996-2001, como se vio en la sección precedente. En este sentido, pareciera que aquellos países que muestran menos déficits de arrastre de la inversión total en infraestructura son los que conservaron niveles significativos de inversión pública (caso de Colombia) o la disminuyeron en menor medida (caso de Chile). Ello no obstante que ambos países se caracterizan por haber aplicado profundas reformas en las diversas áreas de infraestructura, privatizando empresas y desarrollando

GRÁFICO 4

América Latina (países seleccionados): inversión pública en infraestructura como porcentaje del PIB, períodos 1980-1985, 1996-2001, 2002-2006

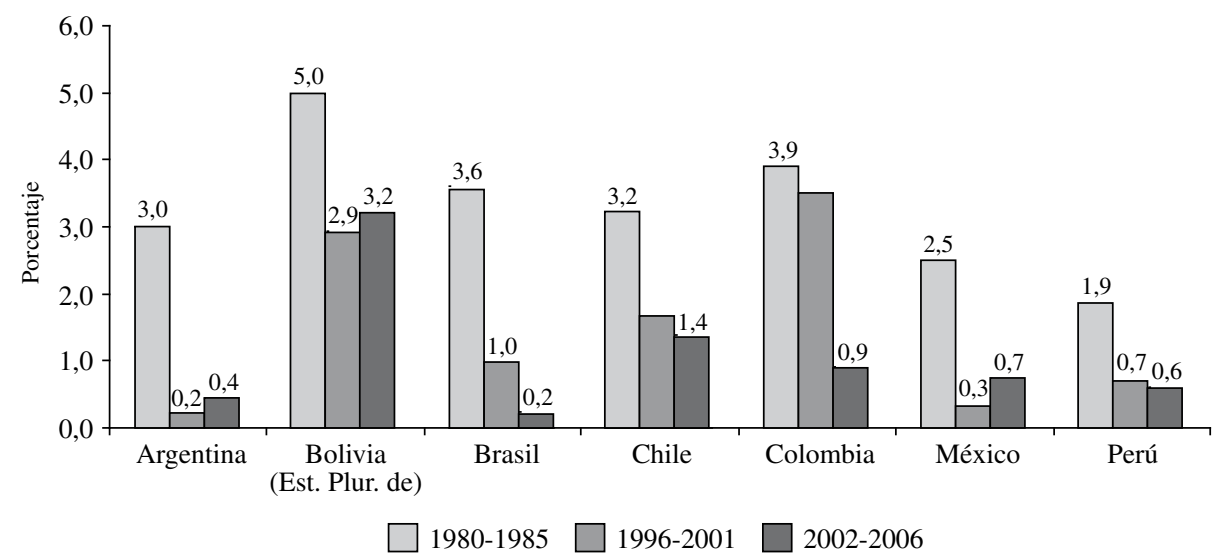

Fuente: períodos 1980-1985 y 1996-2001: César Calderón y Luis Servén, “Trends in infrastructure in Latin America, 1980-2001”, Documento de trabajo, $\mathrm{N}^{\circ}$ 269, Santiago de Chile, Banco Central de Chile, septiembre de 2004; período 2002-2006: elaboración propia sobre la base de datos del Banco Mundial y estadísticas nacionales.

PIB: Producto interno bruto. 
oportunidades de negocios para agentes privados mediante la implementación de modalidades no convencionales de participación, tales como las concesiones viales y otras modalidades de asociaciones público-privadas.

Esto sugiere que la inversión pública no solo puede jugar un papel fundamental en el desarrollo del sector, sino además, que su retracción a niveles mínimos puede ocasionar serios problemas de déficit de inversión en el sector, debido a las insuficiencias y dificultades que han mostrado los agentes privados para sustituir la inversión pública en los niveles demandados por el proceso de crecimiento.

La revisión de la desagregación sectorial de la inversión pública en ambos países refuerza esta idea. En el caso de Chile, la información existente señala que la inversión pública en infraestructura básica se canalizó preferentemente hacia la infraestructura de transporte y lo hizo en el mismo nivel (1\% del PIB) en los quinquenios sometidos a comparación (véase el gráfico 5), lo que contribuyó a atenuar la fuerte caída de la inversión privada entre 2002 y 2006, como se verá más adelante. Esto quiere decir que la aminoración de la inversión pública en infraestructura se produjo preferentemente en telecomunicaciones y energía, áreas en las que el Estado privatizó sus principales activos, y que la inversión pública se mantuvo en aquellas donde el Estado desempeña un papel más activo, tanto en el diseño estratégico del sector como en la planificación de obras y su financiamiento parcial o total, lo que depende del mecanismo de participación privada que se implemente.

En la muestra de economías investigadas, la situación de Chile contrasta notoriamente con las de los demás países de la región incluidos — con la excepción del Estado Plurinacional de Bolivia- donde la inversión pública en infraestructura de transporte terrestre decae a niveles casi marginales (véase el gráfico 6), lo que incidió negativamente en la conservación y renovación de la infraestructura vial existente (según el grado de deterioro, el costo de reposición puede ser incluso más alto que el vinculado a la creación de nuevas obras de infraestructura vial), y en su expansión conforme con los requerimientos del crecimiento del conjunto de la economía (Bull, 2003). En el período más reciente, el esfuerzo desplegado por el gobierno de Chile continuó marcando diferencias con los demás países de la región, con la excepción del Estado Plurinacional de Bolivia, no obstante que en la Argentina, el Brasil y el Perú aumentó significativamente la inversión pública en infraestructura de transporte terrestre, pero sin alcanzar los niveles promedio registrados durante el período 1980-1985.

Las particularidades de Colombia ilustran aún mejor la situación que se analiza: a diferencia de Chile, la inversión pública en infraestructura no se focalizó en un sector determinado, aunque el área de energía continuó siendo su principal receptora, manteniéndose

GRÁFICO 5

Chile: inversión pública en áreas de infraestructura como porcentaje del PIB, períodos 1980-1985, 1996-2001, 2002-2006

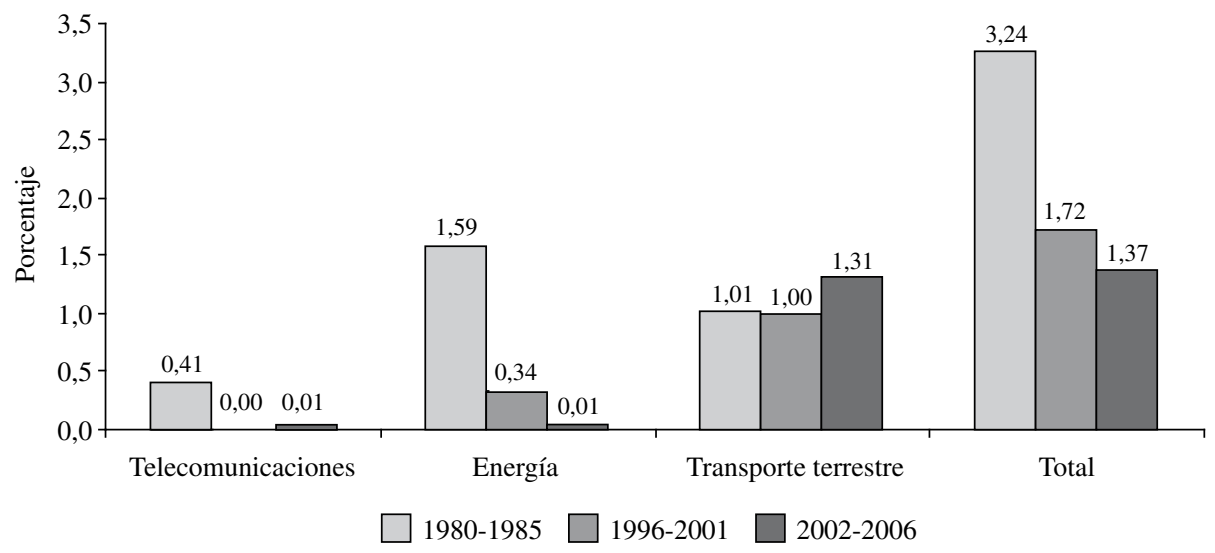

Fuente: períodos 1980-1985 y 1996-2001: César Calderón y Luis Servén, “Trends in infrastructure in Latin America, 1980-2001”, Documento de trabajo, $\mathrm{N}^{\circ}$ 269, Santiago de Chile, Banco Central de Chile, septiembre de 2004; período 2002-2006: elaboración propia sobre la base de datos del Banco Mundial y estadísticas nacionales.

PIB: Producto interno bruto. 
GRÁFICO 6

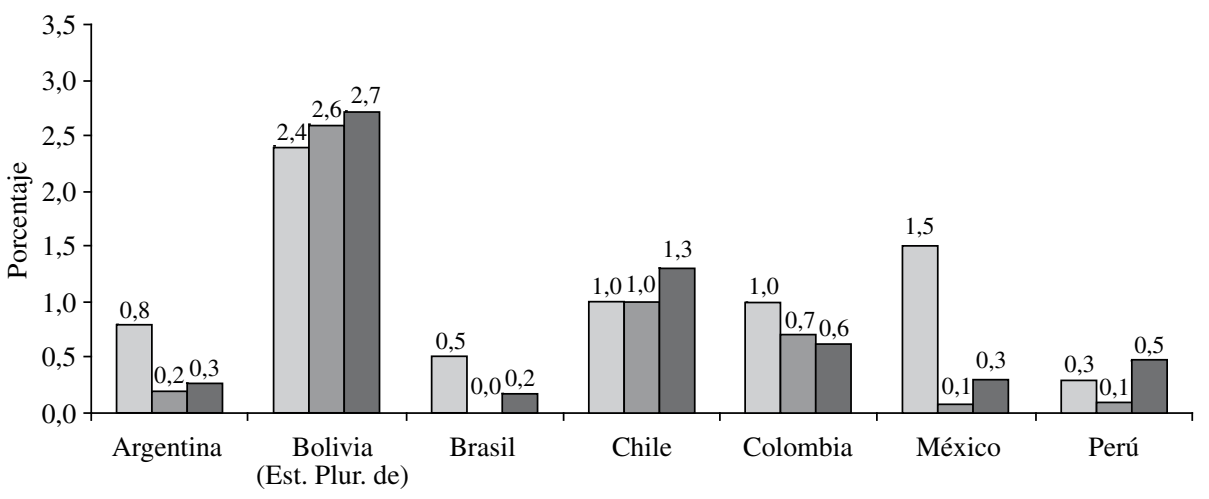

1980-1985 $\square$ 1996-2001 $\square$ 2002-2006

Fuente: períodos 1980-1985 y 1996-2001: César Calderón y Luis Servén, “Trends in infrastructure in Latin America, 1980-2001”, Documento de trabajo, $\mathrm{N}^{\circ} 269$, Santiago de Chile, Banco Central de Chile, septiembre de 2004; período 2002-2006: elaboración propia sobre la base de datos del Banco Mundial y estadísticas nacionales.

PIB: Producto interno bruto.

GRÁFICO 7

Colombia: inversión pública en áreas de infraestructura como porcentaje del PIB, períodos 1980-1985, 1996-2001, 2002-2006

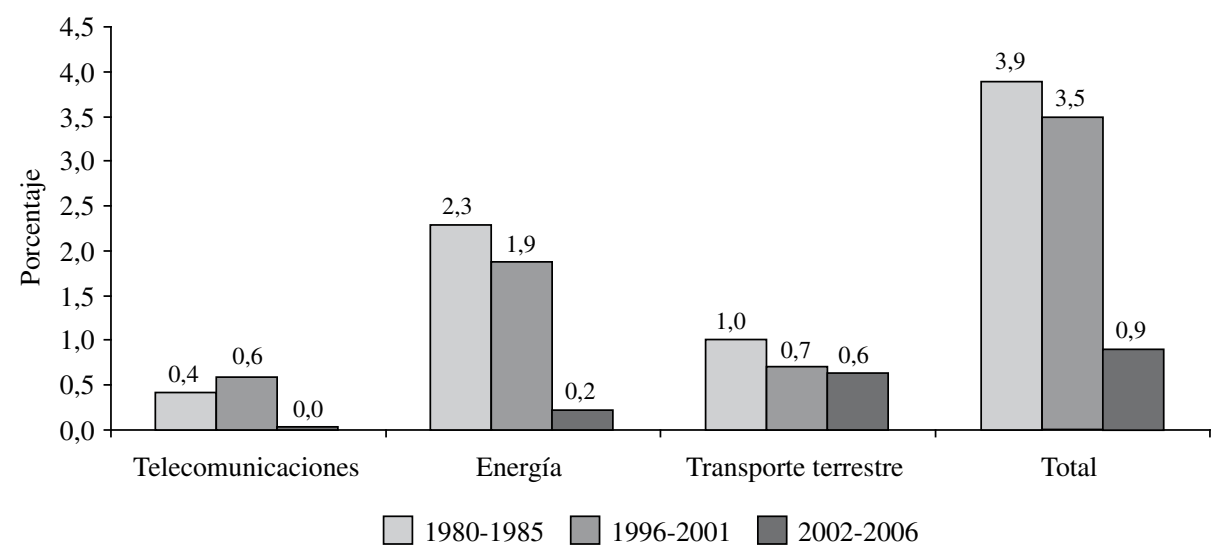

Fuente: períodos 1980-1985 y 1996-2001: César Calderón y Luis Servén, “Trends in infrastructure in Latin America, 1980-2001”, Documento de trabajo, $\mathrm{N}^{\circ}$ 269, Santiago de Chile, Banco Central de Chile, septiembre de 2004; período 2002-2006: elaboración propia sobre la base de datos del Banco Mundial y estadísticas nacionales.

PIB: Producto interno bruto.

en general en niveles levemente inferiores en las áreas más relevantes, e incluso aumentando notoriamente en el área de las telecomunicaciones (véase el gráfico 7). Todo ello contribuyó a que la disminución de la inversión pública en infraestructura básica, en general, no fuera similar a la de los demás países de la región, lo que sumado a la apertura del sector a la participación privada deviniera en el logro de una tasa promedio de inversión en infraestructura de 6\%.

Sin embargo, en el período más reciente (2002-2006) la inversión estatal en el sector se contrajo ostensiblemente, debido sobre todo a la menor participación del 
Estado en la prestación de servicios de energía y de telecomunicaciones. De todos modos, el gobierno de Colombia mantuvo casi el mismo nivel de inversión en transporte terrestre, que se transformó en la principal área receptora de recursos públicos.

En definitiva, en el caso de Colombia, este comportamiento de la inversión pública contribuyó de manera decisiva a que la participación de inversionistas privados se tradujera en un incremento significativo de la inversión total en el sector y no fuese solo un sustituto parcial de una alicaída inversión pública. En el quinquenio siguiente esta perdió relevancia, lo que incidió en que disminuyera significativamente la tasa promedio de inversión en el sector, siguiendo el derrotero de los demás países de la región.

\section{Evolución de la inversión privada}

En líneas generales, en la década de 1990 se produjo un importante flujo de inversión privada en infraestructura, siendo especialmente importante la dinámica alcanzada por este proceso en América Latina, que capturó la mitad de la inversión privada que se dirigió a esta actividad en el mundo en desarrollo. El máximo flujo de inversión privada en infraestructura que sumaron las privatizaciones, las concesiones y otras modalidades de asociaciones públicoprivadas (APP), se alcanzó en 1998 y totalizó casi 67.000 millones de dólares. A pesar de su magnitud sin precedentes en la historia latinoamericana, equivalió a solo el 3,87\% del PIB regional y no logró, por lo tanto, compensar la reducción de la inversión pública, especialmente en las economías regionales de mayor tamaño relativo.

Durante el trienio 1999-2001, la inversión privada en infraestructura disminuyó a casi la mitad del monto registrado en 1998, como consecuencia de las dificultades enfrentadas por algunos países de la región en el ámbito energético y del impacto provocado por el desequilibrio de algunos factores macroeconómicos y el término del proceso privatizador en las principales economías latinoamericanas. Además, esta declinación se acentuó durante el bienio 2002-2003 con motivo de la crisis suscitada principalmente en los países de la costa atlántica de América del Sur, que afectó seriamente el comportamiento de la demanda agregada en dichos países - sobre todo el ingreso de las personas y el gasto en consumo por efecto de la contracción salarial y el mayor desempleo-y la inversión. La recuperación posterior, iniciada en 2004, restableció recién en 2007 los niveles de inversión previos a la crisis de 2002-2003, lo que incluso puede resultar efímero en el nuevo escenario internacional que se ha configurado a partir de 2008.
Algunos analistas prefieren enfocar el tema desde una perspectiva diferente y señalan que la disminución de la inversión pública en infraestructura producida en los años noventa se ha visto parcialmente compensada por una mayor participación privada en la actividad. Aunque esto es cierto, dicha línea de análisis contribuye a minimizar la caída de la inversión en el sector y a sobrevalorar la importancia del traspaso de activos (privatizaciones y adquisiciones), componente esencial de la inversión privada que no repercute directamente en la formación de capital fijo (acervo de capital de infraestructura).

De todos modos, debe tenerse presente que los procesos de privatización iniciados en los países de la región hacia finales de los años ochenta fueron el primer impulso significativo para la incorporación de capital privado en el sector de infraestructura. Cerca del $55 \%$ del valor de las privatizaciones efectuadas en los años noventa corresponde a la enajenación de activos estatales de estos sectores, tradicionalmente cerrados al sector privado (Lora, 2001; Rozas, 2005). Asimismo, las concesiones han sido otro mecanismo que ha posibilitado la incorporación de agentes privados en el financiamiento, construcción y gestión de los servicios de infraestructura, particularmente desde mediados del decenio de 1990. En alguna medida, las concesiones sustituyeron a las privatizaciones como un mecanismo de atracción de capitales privados, especialmente extranjeros, que los gobiernos de algunos países de la región emplearon para aliviar la presión sobre sus respectivas balanzas de pagos, una vez agotados los activos físicos que podían vender.

Impulsados por las privatizaciones - especialmente en el Brasil-y las operaciones de adquisición (take-over) en el área de energía, los flujos de inversión privada en infraestructura aumentaron notablemente entre 1995 y 1998 de 14.000 millones de dólares a 67.000 millones de dólares. Las mayores cifras agregadas de inversión en el sector se registraron en 1997 y 1998, generadas principalmente por la venta de las empresas de telecomunicaciones y eléctricas de Brasil, la toma de control del grupo chileno Enersis por parte de la Empresa Nacional de Electricidad, S.A. (ENDESA) y el desarrollo de las concesiones viales en varios de los países de la región: la Argentina, Chile, Colombia y México.

El incremento de la inversión privada en infraestructura se produjo prácticamente en todos los países de la región, lo que resulta razonable si se asume que la participación de capitales privados estaba vedada o restringida en la mayoría de las áreas de infraestructura hasta la puesta en marcha de las reformas. Conforme 
GRÁFICO 8

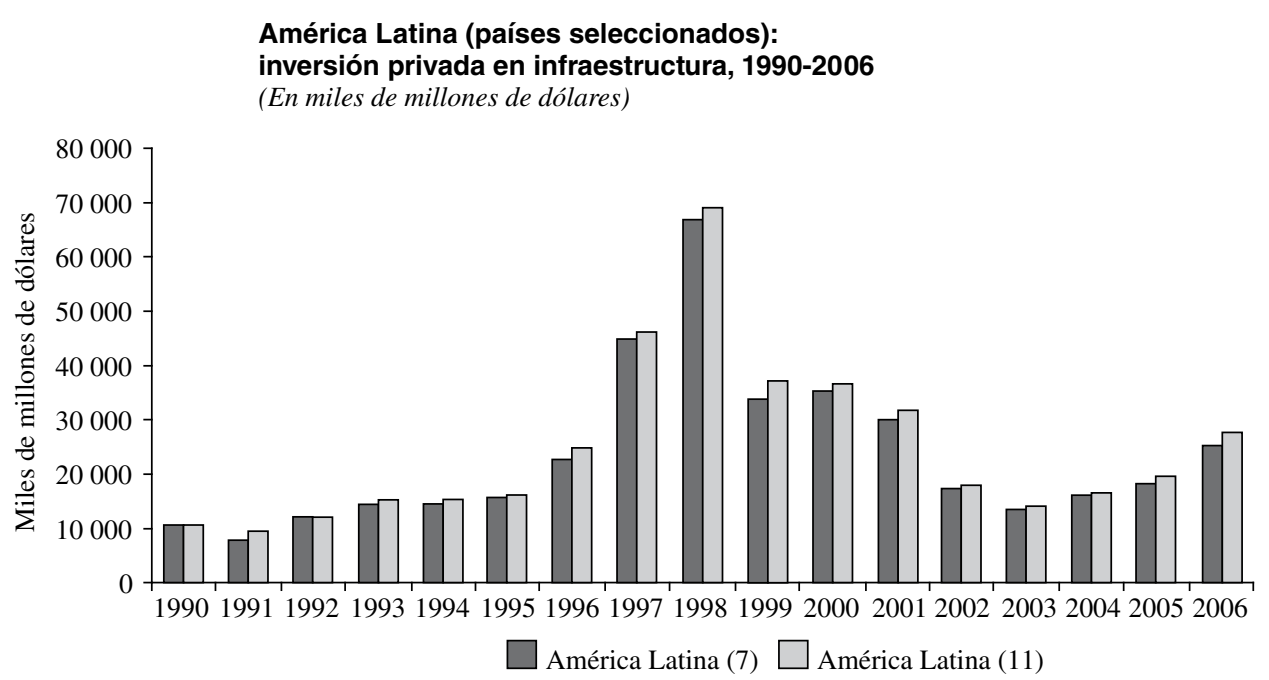

Fuente: elaboración propia sobre la base de datos del Banco Mundial.

Nota: En América Latina (7) se incluye a la Argentina, el Brasil, Chile, Colombia, el Estado Plurinacional de Bolivia, México y el Perú; en América Latina (11) se agrega al Ecuador, el Paraguay, la República Bolivariana de Venezuela y el Uruguay.

GRÁFICO 9

\section{América Latina ${ }^{a}$ : distribución de la inversión privada por áreas de infraestructura en las principales economías (En porcentajes)}

1990-2006

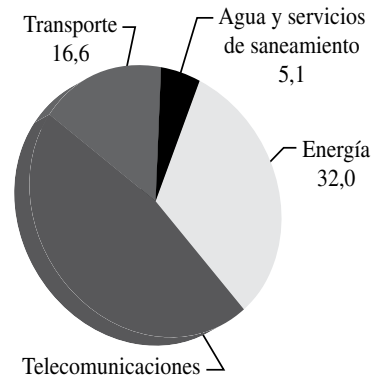

46,2
2002-2006

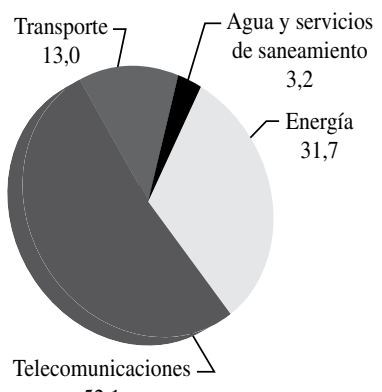

52,1

Fuente: elaboración propia sobre la base de datos del Banco Mundial.

a Incluye a la Argentina, el Brasil, Chile, Colombia, el Estado Plurinacional de Bolivia, México y el Perú.

con los datos del Banco Mundial, la inversión privada se dirigió principalmente a las áreas de energía y telecomunicaciones, sectores que alcanzaron una participación de $46,2 \%$ y $32 \%$, respectivamente, del total invertido por agentes privados en el sector durante el período 1990-2006. En el lapso más reciente, de 2002 a 2006, esta tendencia se acentuó, sobre todo la participación de las telecomunicaciones, que constituyeron el $52,1 \%$ de la inversión privada en el sector.

Los antecedentes presentados en el estudio de Calderón y Servén (2004) relativizaron la importancia adquirida por los inversionistas privados en los totales de inversión orientados a la infraestructura de la región. Según ambos autores, la inversión privada en el sector aumentó de 0,61\% del PIB (promedio anual del período 1980-1985) a 1,41\% del PIB (promedio anual del período 1996-2001). Aunque este incremento de la inversión privada en infraestructura entre ambos quinquenios ha sido especialmente destacado como expresión del papel más activo de las empresas privadas en el desarrollo del sector ( $131 \%$ de incremento), no se debe dejar de considerar que dicho aumento fue de solo 0,8 puntos porcentuales 
del PIB, muy inferior a la disminución registrada por la inversión pública promedio entre ambos períodos ( $-2,27$ puntos porcentuales). Los datos posteriores confirman que su relevancia en el financiamiento de la infraestructura ha sido todavía menos significativa en el período siguiente (2002-2006), cuando la inversión privada representó apenas un 0,9\% del PIB promedio de las principales economías de la región.

La inversión privada creció notoriamente en el área de las telecomunicaciones, no así en energía y en transporte terrestre, actividades en que la participación privada no presenta variaciones significativas (véase el gráfico 10). En cambio, en las telecomunicaciones el peso relativo de la inversión privada se cuadruplicó, aumentando de $0,2 \%$ a $0,8 \%$ del PIB. Este incremento refleja en gran medida el éxito alcanzado por el Gobierno de Brasil tanto en relación con la privatización de Telecomunicaciones Brasileñas, S.A. (TELEBRAS) — que marcó un hito en la venta de empresas estatales en América Latina - como con respecto a la organización de la industria de la telefonía móvil, que desató una gran afluencia de inversión extranjera en el sector (Rozas, 2005).

Además, este incremento del peso relativo de la participación privada en telecomunicaciones influyó para que también en los demás países —especialmente en la Argentina, Chile, Colombia, México y el Perúse elevara la participación privada en la inversión en el sector como resultado de la privatización de las principales empresas operadoras de telefonía. En un estudio sobre este proceso se estableció que la venta de los monopolios de telecomunicaciones producida entre 1986 y 2004 generó ingresos fiscales por 42.000 millones de dólares, la mayor parte durante los años noventa (Rozas, 2005).

En el período posterior, la inversión privada en telecomunicaciones medida como porcentaje del PIB se redujo notoriamente, disminuyendo de $0,77 \%$ a $0,47 \%$ del PIB, por haberse puesto término a la privatización de las empresas públicas del sector en la mayoría de los países de la región. No obstante, esta actividad siguió siendo el área de infraestructura que recibió más inversión privada, lo que se vinculó con el desarrollo de nuevos negocios y con los escenarios de competencia brindados por las nuevas tecnologías y el progresivo deterioro de las economías de escala de la telefonía básica. Dicha disminución se produjo en todos los países que constituyen la muestra investigada y fue particularmente relevante en Chile, país que muestra uno de los niveles de penetración telefónica más altos de la región, lo que sugiere que las inversiones en telecomunicaciones han empezado a alcanzar un cierto techo como consecuencia de la progresiva maduración de sus mercados.

Por cierto, cabe discutir hasta qué punto es admisible considerar inversión los capitales vinculados a los traspasos de propiedad de las empresas estatales que fueron privatizadas y que constituyen buena parte de lo que algunos analistas reconocen como "inversión privada", aunque dichas transacciones no inciden directamente en

GRÁFICO 10

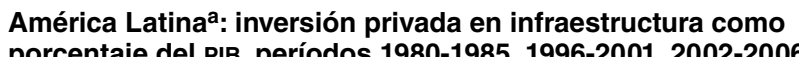
porcentaje del PIB, períodos 1980-1985, 1996-2001, 2002-2006

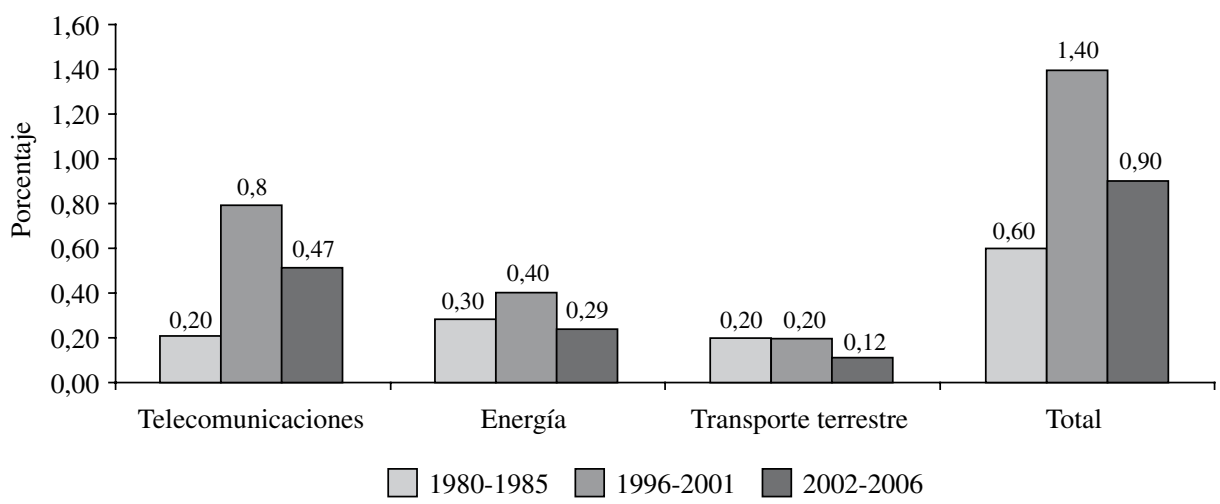

Fuente: períodos 1980-1985 y 1996-2001: César Calderón y Luis Servén, “Trends in infrastructure in Latin America, 1980-2001”, Documento de trabajo, $\mathrm{N}^{\circ}$ 269, Santiago de Chile, Banco Central de Chile, septiembre de 2004; período 2002-2006: elaboración propia sobre la base de datos del Banco Mundial y estadísticas nacionales.

a Incluye a la Argentina, el Brasil, Chile, Colombia, el Estado Plurinacional de Bolivia, México y el Perú.

PIB: Producto interno bruto. 


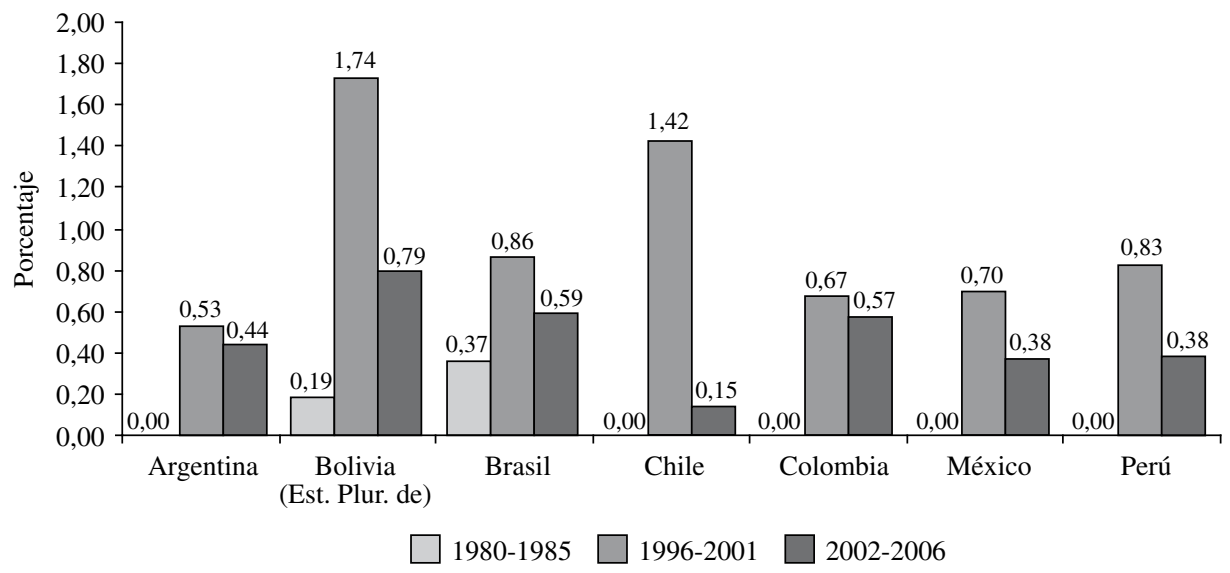

Fuente: períodos 1980-1985 y 1996-2001: César Calderón y Luis Servén, “Trends in infrastructure in Latin America, 1980-2001”, Documento de trabajo, $\mathrm{N}^{\circ}$ 269, Santiago de Chile, Banco Central de Chile, septiembre de 2004. Período 2002-2006: elaboración propia sobre la base de datos del Banco Mundial y estadísticas nacionales.

PIB: Producto interno bruto.

la formación bruta de capital o aumento de la capacidad productiva. En estricto rigor, la mayoría de las veces el destino de los recursos que generó la venta de tales empresas fue el financiamiento del gasto corriente de los gobiernos y no el incremento de la infraestructura del sector. En este sentido, sería recomendable que los países diferenciaran entre los recursos empleados por los inversionistas para la compra de acciones o derechos de propiedad y aquellos ocupados para constituir, ampliar o modernizar la capacidad productiva de la empresa adquirida. En tal caso, probablemente los países latinoamericanos mostrarían estadísticas muy distintas a las existentes.

Asimismo, cabe preguntarse a qué obedece que en la inversión promedio realizada en la industria de telecomunicaciones —más allá de lo espurias que pueden resultar las cifras disponibles- el peso relativo de los agentes privados se haya cuadruplicado y no haya ocurrido lo mismo en otras áreas de la industria de infraestructura.

La CEPAL ha sostenido que las razones de esta diferencia pueden encontrarse en los distintos montos que son necesarios para generar una unidad de ingreso anual (CEPAL, 2004). Siguiendo las estimaciones del Banco Mundial, la CEPAL ha señalado que son las telecomunicaciones y las empresas de energía — principalmente eléctricas- las actividades de infraestructura que requieren un menor monto de capital para generar una unidad de ingreso anual (CEPAL, 2004). De esta manera, actividades tales como la construcción y conservación de carreteras, y la construcción de redes de abastecimiento de agua potable y demás servicios de saneamiento son menos atractivas para los inversionistas privados, ya sea por el mayor monto que deben invertir para generar una unidad de ingreso anual, ya sea debido al mayor tiempo que deben asignar para lograr el retorno de la inversión.

Esta explicación, sin embargo, no es aplicable al sector energía, en el que el peso relativo de la inversión privada solo tuvo un leve incremento, transitando de 0,31\% del PIB (promedio anual del período 1980-1985)

CUADRO 1 Financiamiento necesario para generar
una unidad de ingreso anual

\begin{tabular}{lc}
\hline & 2002 \\
\hline Energía & 3 \\
Telecomunicaciones & $3-4$ \\
Transporte & 7 \\
Agua y saneamiento & $10-12$ \\
\hline
\end{tabular}

Fuente: Comisión Económica para América Latina y el Caribe (CEPAL), Desarrollo productivo en economías abiertas (LC/G.2234(SES.30/3), Santiago de Chile (2004), sobre la base de estimaciones del Banco Mundial. 
a 0,37\% del PIB (promedio anual del período 19962001) y a $0,29 \%$ del PIB (promedio anual del período 2002-2006). Las causas probables de este desempeño se relacionan con diversos problemas de índole regulatoria y de organización de los mercados internacionales de energía, como lo prueban algunos trabajos recientes (Rozas, 2008a).

En síntesis, el significativo incremento de la inversión privada en infraestructura se focalizó en telecomunicaciones, única actividad en que logró sustituir a la inversión pública y dinamizar notoriamente su desarrollo y modernización. En las demás actividades, el aumento del peso relativo de los agentes privados en los niveles de inversión fue de menor cuantía y significación, lo que devino, en un escenario caracterizado por políticas fiscales restrictivas, en una importante contracción de la inversión en infraestructura en varios de los países de la región, especialmente en los de mayor relevancia cuantitativa.

A pesar de las insuficiencias anotadas, las políticas de promoción de la inversión privada en la industria de infraestructura sí lograron transformar la estructura económica de los mercados de los servicios relacionados. Según un estudio de Andrés, Foster y Guasch (2006), a inicios del año 2000, el 86\% de los clientes de las telecomunicaciones, el $60 \%$ de los clientes de la electricidad y el $11 \%$ de los del agua potable eran atendidos por empresas privadas. Esto contrasta con el bajo nivel de clientes atendidos por empresas privadas antes de 1990, estimado en menos de un 3\%.

CUADRO 2

América Latina: inversión en infraestructura como porcentaje del PIB (En porcentajes)

\begin{tabular}{|c|c|c|c|c|c|c|c|c|c|c|c|c|c|}
\hline \multirow{2}{*}{ País } & \multirow{2}{*}{ Período } & \multicolumn{3}{|c|}{ Telecomunicaciones } & \multicolumn{3}{|c|}{ Energía } & \multicolumn{3}{|c|}{ Transporte terrestre } & \multicolumn{3}{|c|}{ Total de la infraestructura } \\
\hline & & Total & Público & Privado & Total & Público & Privado & Total & Público & Privado & Total & Público & Privado \\
\hline \multirow[t]{3}{*}{ Argentina } & 1980-1985 & 0,33 & 0,33 & 0,00 & 1,57 & 1,57 & 0,00 & 0,84 & 0,84 & 0,00 & 2,96 & 2,96 & 0,00 \\
\hline & $1996-2001$ & 0,53 & 0,00 & 0,53 & 0,40 & 0,03 & 0,36 & 0,32 & 0,15 & 0,17 & 1,45 & 0,22 & 1,24 \\
\hline & $2002-2006$ & 0,44 & 0,00 & 0,44 & 0,46 & 0,12 & 0,34 & 0,32 & 0,27 & 0,04 & 1,26 & 0,42 & 0,83 \\
\hline \multirow[t]{3}{*}{ Brasil } & $1980-1985$ & 0,69 & 0,32 & 0,37 & 3,32 & 2,53 & 0,79 & 0,84 & 0,47 & 0,37 & 5,17 & 3,64 & 1,53 \\
\hline & 1996-2001 & 1,16 & 0,30 & 0,86 & 0,76 & 0,37 & 0,39 & 0,14 & 0,04 & 0,10 & 2,39 & 1,02 & 1,37 \\
\hline & $2002-2006^{\mathrm{a}}$ & 0,60 & 0,01 & 0,59 & 0,43 & 0,00 & 0,43 & 0,23 & 0,18 & 0,05 & 1,31 & 0,23 & 1,08 \\
\hline \multirow[t]{3}{*}{ Chile } & $1980-1985$ & 0,41 & 0,41 & 0,00 & 1,59 & 1,59 & 0,00 & 1,01 & 1,01 & 0,00 & 3,24 & 3,24 & 0,00 \\
\hline & $1996-2001$ & 1,42 & 0,00 & 1,42 & 1,78 & 0,34 & 1,44 & 1,96 & 1,00 & 0,96 & 5,58 & 1,72 & 3,86 \\
\hline & $2002-2006$ & 0,16 & 0,01 & 0,15 & 0,14 & 0,01 & 0,13 & 1,79 & 1,31 & 0,48 & 2,28 & 1,37 & 0,91 \\
\hline \multirow[t]{3}{*}{ Colombia } & $1980-1985$ & 0,36 & 0,36 & 0,00 & 2,32 & 2,32 & 0,00 & 0,99 & 0,99 & 0,00 & 3,85 & 3,85 & 0,00 \\
\hline & $1996-2001$ & 1,25 & 0,58 & 0,67 & 3,32 & 1,91 & 1,41 & 0,89 & 0,69 & 0,21 & 5,76 & 3,48 & 2,28 \\
\hline & $2002-2006$ & 0,60 & 0,02 & 0,57 & 0,28 & 0,21 & 0,07 & 0,84 & 0,63 & 0,20 & 1,88 & 0,92 & 0,96 \\
\hline \multirow[t]{3}{*}{ México } & $1980-1985$ & 0,24 & 0,24 & 0,00 & 0,49 & 0,49 & 0,00 & 1,54 & 1,54 & 0,00 & 2,45 & 2,45 & 0,00 \\
\hline & $1996-2001$ & 0,73 & 0,03 & 0,70 & 0,11 & 0,11 & 0,00 & 0,34 & 0,08 & 0,27 & 1,24 & 0,27 & 0,98 \\
\hline & $2002-2006$ & 0,38 & 0,00 & 0,38 & 0,44 & 0,31 & 0,13 & 0,41 & 0,28 & 0,12 & 1,37 & 0,73 & 0,64 \\
\hline \multirow[t]{3}{*}{ Perú } & $1980-1985$ & 0,31 & 0,31 & 0,00 & 1,29 & 1,28 & 0,01 & 0,33 & 0,30 & 0,03 & 1,98 & 1,94 & 0,04 \\
\hline & $1996-2001$ & 1,07 & 0,24 & 0,83 & 0,94 & 0,32 & 0,63 & 0,25 & 0,12 & 0,13 & 2,28 & 0,68 & 1,60 \\
\hline & $2002-2006$ & 0,39 & 0,00 & 0,38 & 0,65 & 0,07 & 0,58 & 0,88 & 0,47 & 0,41 & 2,02 & 0,61 & 1,41 \\
\hline \multirow{4}{*}{$\begin{array}{l}\text { Bolivia } \\
\text { (Est. Plur. de) }\end{array}$} & & & & & & & & & & & & & \\
\hline & $1980-1985$ & 0,89 & 0,70 & 0,19 & 1,90 & 1,75 & 0,14 & 2,81 & 2,40 & 0,41 & 5,79 & 5,04 & 0,76 \\
\hline & 1996-2001 & 1,74 & 0,00 & 1,74 & 1,75 & 0,22 & 1,53 & 2,78 & 2,61 & 0,17 & 7,28 & 2,93 & 4,35 \\
\hline & $2002-2006$ & 0,80 & 0,00 & 0,79 & 1,66 & 0,17 & 1,49 & 2,71 & 2,71 & 0,00 & 5,50 & 3,21 & 2,29 \\
\hline \multirow[t]{3}{*}{ Promedio } & $1980-1985$ & 0,45 & 0,30 & 0,15 & 1,95 & 1,64 & 0,31 & 1,06 & 0,91 & 0,15 & 3,71 & 3,10 & 0,61 \\
\hline & $1996-2001$ & 0,94 & 0,17 & 0,77 & 0,71 & 0,31 & 0,37 & 0,36 & 0,16 & 0,20 & 2,24 & 0,83 & 1,41 \\
\hline & $2002-2006$ & 0,47 & 0,01 & 0,47 & 0,43 & 0,14 & 0,29 & 0,45 & 0,33 & 0,12 & 1,46 & 0,56 & 0,90 \\
\hline
\end{tabular}

Fuente: períodos 1980-1985 y 1996-2001: César Calderón y Luis Servén, “Trends in infrastructure in Latin America, 1980-2001”, Documento de trabajo, № 269, Santiago de Chile, Banco Central de Chile, septiembre de 2004. Período 2002-2006: elaboración propia sobre la base de datos del Banco Mundial y estadísticas nacionales.

a El nivel de inversión pública corresponde al período 2004-2006.

PIB: Producto interno bruto. 


\section{Financiamiento multilateral}

Durante los años noventa, los organismos multilaterales de crédito rebajaron sustantivamente los montos de recursos que eran destinados al financiamiento de obras de infraestructura en América Latina, aunque se incrementaron los préstamos orientados al perfeccionamiento de las políticas sectoriales y el fortalecimiento institucional de los gobiernos. En general, la disminución de los créditos destinados al financiamiento de obras de infraestructura fue consecuencia de una política que privilegió objetivos de asistencia a las autoridades sectoriales de cada país de la región, en desmedro del papel de inversor que desempeñaba el Estado en el sector. Consecuentemente, la asistencia prestada se focalizó en el diseño de políticas e instrumentos cuyos objetivos eran la multiplicación de los flujos de inversión privada en el sector.

Esta decisión se sustentó en un claro error de diagnóstico en una doble perspectiva: por una parte, no se asignó la debida importancia a la creación y conservación de infraestructura como un factor esencial del crecimiento y el desarrollo, por sus efectos en la productividad de los agentes económicos y en la competitividad de las empresas, las industrias y las economías en su conjunto; por otra, se sobrevaloró el papel que desempeñarían los agentes privados en la creación y conservación de infraestructura una vez terminado el proceso de privatización de los principales activos del sector o de entrega en concesión.
En el caso particular del Banco Interamericano de Desarrollo (BID), la estrategia de mayor asistencia institucional y menor participación en el financiamiento multilateral se acentuó firmemente a fines de los años noventa, como se observa en el gráfico siguiente, revirtiéndose esta tendencia solo en 2005. Antes de ese año, los créditos otorgados a los gobiernos se redujeron durante el sexenio 1999-2004 a una mínima fracción de los montos asignados en 1997 y 1998 . Asimismo, en el período señalado también se redujeron los créditos otorgados a empresas privadas.

Sin embargo, cabe señalar que los organismos multilaterales de crédito de la región tuvieron un desempeño distinto a los mostrados por el Banco Mundial o el BID durante este período, poniendo en ejecución una política de colocaciones más de acuerdo con las necesidades de los países accionistas. Este fue el caso, por ejemplo, de la Corporación Andina de Fomento (CAF), que aumentó notoriamente sus préstamos en América Latina a partir de 1990, pasando de 500 millones de dólares en 1990 a 5.500 millones de dólares en 2006 (véase el gráfico 13).

Una parte importante de las colocaciones de la CAF en América Latina la constituyen los créditos destinados al financiamiento de infraestructura, línea de negocios que recién empezó a desarrollar en 1990. Durante el quinquenio 2002-2006, las colocaciones de la CAF en infraestructura alcanzaron una clara preeminencia respecto de otros sectores, representando

GRÁFICO 12

Colocaciones del Banco Interamericano de Desarrollo (BID) en América Latina por tipo de receptor, 1995-2006

(En miles de millones de dólares)

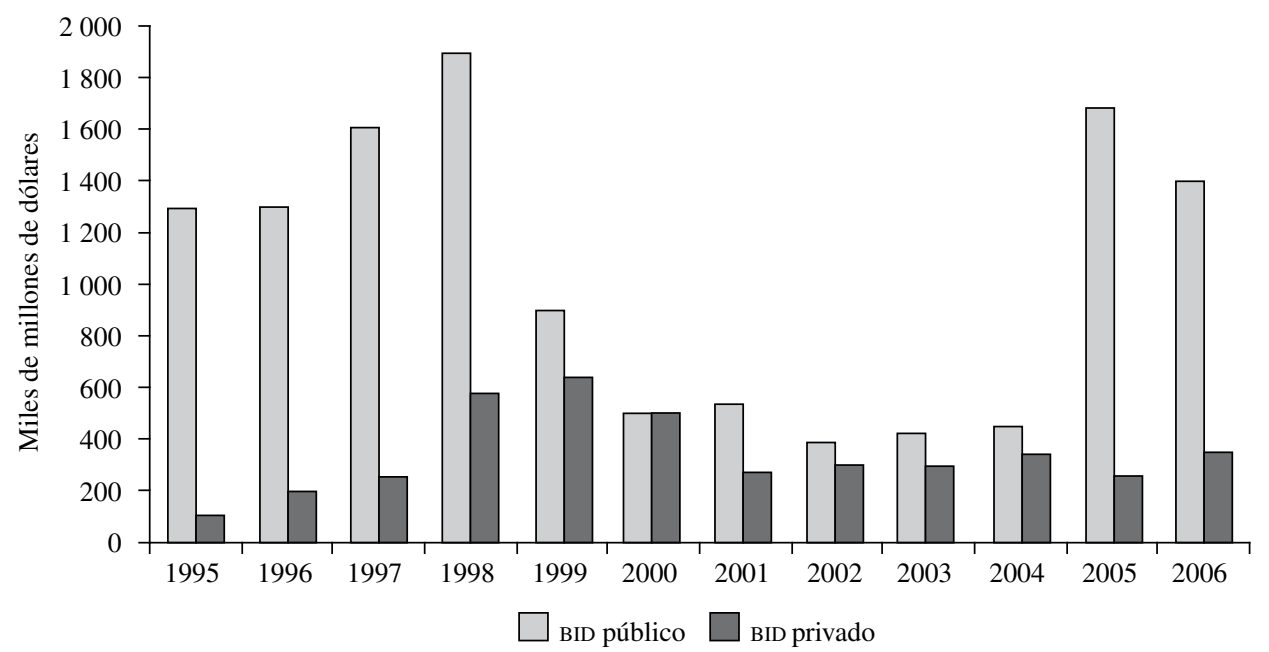

Fuente: Roberto Vellutini, “Financiamento a infraestructura e parceiras público-privadas no setor de energia”, Río de Janeiro, 2007. 

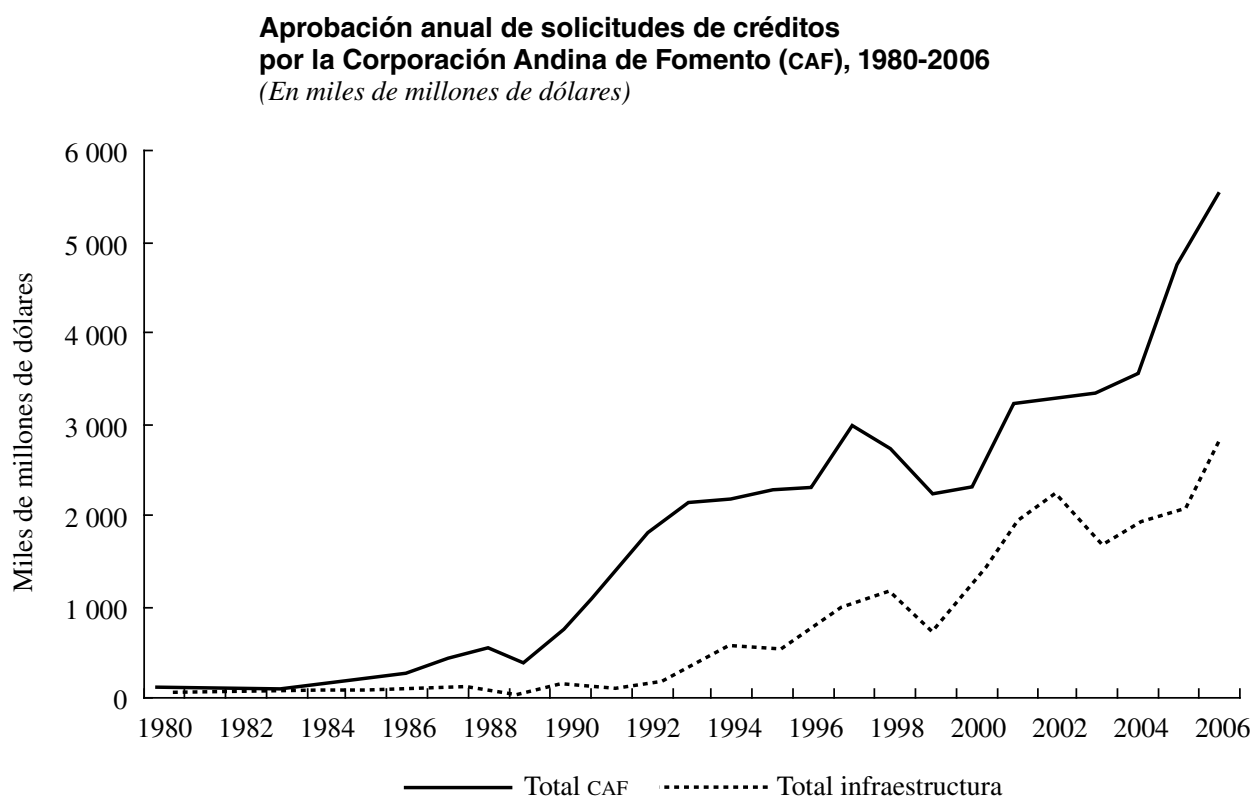

Fuente: J. Kogan, "Financiamiento de la infraestructura: principales desafíos de las alianzas público-privadas y de la regulación de los mercados", presentación en el Seminario Internacional "Infraestructura 2020: avances, déficits y desafíos" (CEPAL, Santiago de Chile, 10 de noviembre de 2008), 2008.

el $52 \%$ del total de las colocaciones aprobadas. Este valor supera con creces el correspondiente a períodos anteriores (47\% en el período 1997-2001; $25 \%$ en el lapso 1992-1996), poniendo en evidencia la importancia creciente de la infraestructura en las líneas de negocios que la CAF apoya (Kogan, 2008). En 2006 -último año del que se dispone información- las colocaciones de la CAF en infraestructura ascendieron a poco menos de 3.000 millones de dólares y superaron notoriamente a las colocaciones del BID. En general, los préstamos orientados al sector han seguido una curva ascendente, con la excepción de los años 1999 y 2003, cuando algunos países de la región debieron enfrentar diversas dificultades y redujeron en consecuencia su demanda de créditos para el desarrollo de proyectos de infraestructura. A pesar de los antecedentes expuestos debe anotarse, empero, que la colocación de los préstamos se concentra en un pequeño grupo de países (Colombia, el Ecuador, el Estado Plurinacional de Bolivia, el Perú, y la República Bolivariana de Venezuela, y representan el destino del $78 \%$ de las colocaciones aprobadas) y se dirige mayoritariamente a un sector (transporte: 68\%).

\section{III}

\section{Efectos de las dificultades del proceso inversor en el sector de infraestructura en América Latina}

La declinación de la inversión en infraestructura -especialmente en la infraestructura de transporte terrestre y en algunos países de América Latina con más énfasis que en otros- ha provocado dos tipos de efectos que lesionan tanto la productividad de los agentes económicos como la competitividad de las industrias y las economías de la región, al tiempo que impiden una mejor calidad de vida de las personas:

i) Un creciente rezago en la dotación de infraestructura y en la provisión de servicios no solo 
respecto de los países desarrollados, sino también de otras economías en desarrollo (o emergentes) que a comienzos de los años setenta presentaban niveles de provisión de servicios más bajos que los de América Latina.

ii) La declinación de la inversión en las diversas áreas de infraestructura, con la excepción de las telecomunicaciones, ha producido diversos efectos sobre la calidad de los servicios prestados, que también son percibidos por los usuarios como inferiores a los observados en otras economías emergentes.

\section{Rezago con respecto de otras economías emergentes}

A pesar de los avances logrados en el sector de infraestructura en la mayoría de los países de la región en el transcurso de los últimos 25 años, se observa un claro rezago con respecto a los países desarrollados y a los países de crecimiento más dinámico del sudeste de Asia, en términos de la evolución del acervo y calidad de sus sistemas de infraestructura, así como en la cobertura de los servicios públicos.

Como se puede observar en el cuadro 3, las diferencias en el acervo (stock) de capital en infraestructura entre América Latina y el sudeste asiático aumentaron significativamente entre 1980 y 2005, acentuándose la brecha que ya existía en favor de los países asiáticos en los segmentos de energía eléctrica y de telecomunicaciones, a la vez que se revirtió la ventaja que los países latinoamericanos tenían sobre sus pares asiáticos en el transporte terrestre.

En el área energética, no obstante que los países latinoamericanos aumentaron su capacidad de generación de electricidad por habitante en $57,7 \%$ entre 1980 y el año 2000 , y en $80,8 \%$ entre 1980 y 2005 , los países del sudeste asiático acrecentaron la suya en $239 \%$ entre 1980 y el año 2000, y en 300\% entre 1980 y 2005. Esto determinó que la brecha existente en 1980, que ascendía al $38,5 \%$, se incrementara al $197,6 \%$ en el año 2000 y al 206,4\% en 2005 (véase el gráfico 14).

Puesto en otros términos, el aumento de la capacidad de generación eléctrica de los países del sudeste asiático durante el período 1980-2005 superó con creces el de los países latinoamericanos, al punto que hacia 2005 la capacidad de generación de los países del sudeste asiático ya triplicaba la de los países latinoamericanos, en circunstancias que en 1980 la mayor capacidad de aquellos era de solo el 36\% en relación con estos últimos.

En el área de las telecomunicaciones pasó algo similar, aunque con algunas diferencias importantes que
CUADRO 3

\section{América Latina $^{a}$ y sudeste de Asiab: acervo de capital de infraestructura, años seleccionados}

\begin{tabular}{lccccc}
\hline & 1980 & 1990 & 1995 & 2000 & 2005 \\
\hline Energía $^{c}$ & & & & & \\
América Latina (22) & 0,26 & 0,36 & 0,38 & 0,41 & 0,47 \\
América Latina (7) & 0,27 & 0,34 & 0,36 & 0,40 & 0,47 \\
$\quad$ Sudeste de Asia & 0,36 & 0,67 & 0,84 & 1,22 & 1,44 \\
Telecomunicaciones & & & & & \\
América Latina (22) & 39,4 & 61,7 & 97,0 & 271,5 & 618,0 \\
América Latina (7) & 41,2 & 64,3 & 100,8 & 287,1 & 647,7 \\
Sudeste de Asia & 108 & 324,5 & 476,2 & 1232 & 1464,1 \\
Transporte terrestre & & & & & \\
América Latina (22) & 1,1 & 1,18 & 0,93 & 0,86 & 0,83 \\
América Latina (7) & $\ldots$ & $\ldots$ & $\ldots$ & 0,77 & 0,76 \\
Sudeste de Asia & 0,58 & 0,87 & 0,95 & 1,71 & 2,06 \\
\hline
\end{tabular}

Fuente: elaboración propia a partir de datos extraídos de la Administración de Información Energética del Departamento de Energía de los Estados Unidos, Unión Internacional de Telecomunicaciones (UIT), Federación Internacional de Carreteras y Energy Information Administration, DOE; International Telecommunication Union, International Road Federation (IRF) y Comisión Económica para América Latina y el Caribe (CEPAL), Desarrollo productivo en economías abiertas (LC/G.2234(SES.30/3)), Santiago de Chile, junio de 2004.

a América Latina (22) incluye a la Argentina, el Brasil, Chile, Colombia, el Estado Plurinacional de Bolivia, Costa Rica, el Ecuador, El Salvador, Guatemala, Guyana, Haití, Honduras, Jamaica, México, Nicaragua, Panamá, el Paraguay, el Perú, la República Bolivariana de Venezuela, Suriname, Trinidad y Tabago y el Uruguay.

América Latina (7) incluye a la Argentina, el Brasil, Chile, Colombia, el Estado Plurinacional de Bolivia, México y el Perú.

b Sudeste de Asia incluye a la República de Corea, Hong Kong (Región Administrativa Especial de China), Singapur y la provincia china de Taiwán.

c Medido como capacidad de generación en kilowatts per cápita.

d Medido como número de teléfonos fijos y celulares (desde 1995) por cada 1.000 habitantes.

e Medido como kilómetros de carreteras pavimentadas per cápita.

sugieren que la tendencia a la profundización de la brecha entre ambos grupos de países puede ser revertida.

A comienzos de los años ochenta, los países del sudeste de Asia ya presentaban un desarrollo suficientemente mayor que el alcanzado por los países de América Latina en esta actividad, con una diferencia de conectividad del 162,4\% entre ambos grupos de países (véase el gráfico 14). En ese entonces, los países latinoamericanos registraban una densidad telefónica de solo 4,1 suscriptores de líneas telefónicas por cada 100 habitantes, mientras que los países del sudeste asiático habían alcanzado una densidad de 10,1 suscriptores por cada 100 habitantes.

Esta brecha creció significativamente en los años ochenta, a consecuencia del fuerte desarrollo que esta actividad alcanzó en los países del sudeste de Asia 


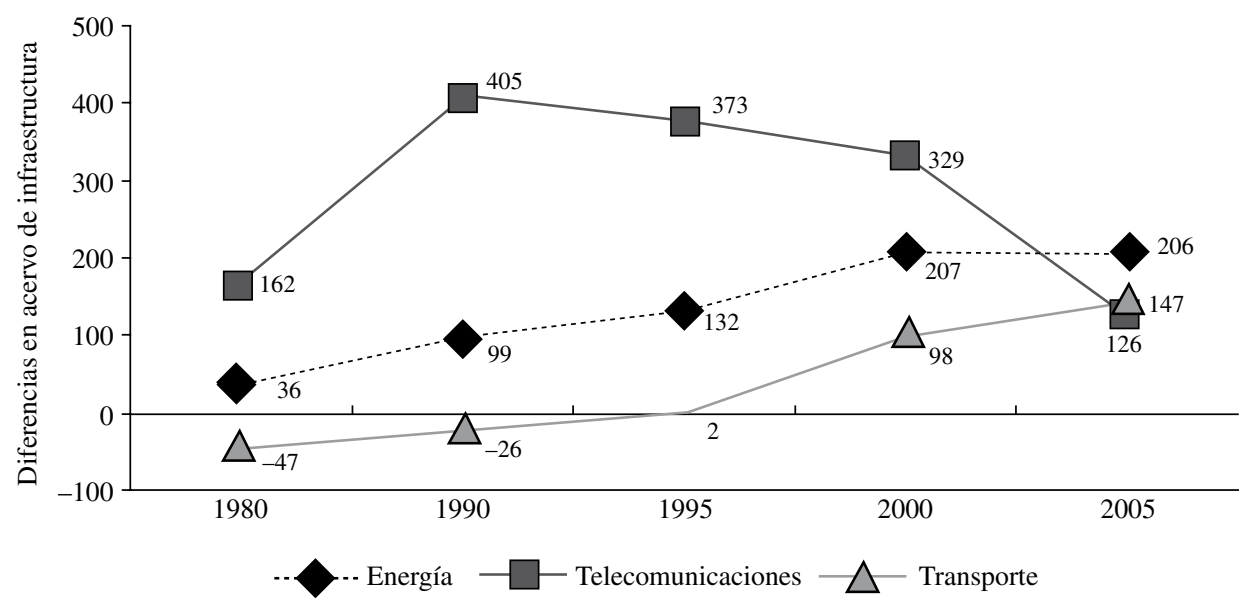

Fuente: elaboración propia sobre la base de los datos presentados en el cuadro 3.

(200,5\%), que cuadruplicó la expansión de las telecomunicaciones en América Latina durante ese período $(56,6 \%)$, estableciéndose una diferencia de $405 \%$ entre sus niveles de desarrollo. Así, mientras que en América Latina la densidad telefónica aumentó a 6,2 suscriptores por cada 100 habitantes, en los países del sudeste asiático esta llegó a 32,4 suscriptores por cada 100 habitantes.

A contar de entonces, primero con lentitud y luego con más rapidez, en el primer lustro de la década de 2000, la brecha disminuyó de manera importante, reduciéndose a 126\%, guarismo inferior al existente en 1980 (véase el gráfico 14). Sin embargo, a pesar de esta aminoración, a fines de 2005 los países del sudeste asiático aún duplicaban con creces la cantidad de suscriptores de líneas telefónicas por cada 100 habitantes registrada en América Latina, y ostentaban en consecuencia un notorio mayor nivel de conectividad en un área que es esencial para la modernización de las estructuras productivas y comerciales de cada país.

La respuesta fácil que tiende a darse acerca de las causas que explican esta importante reducción de la brecha a partir de 1990, pero muy especialmente a partir del año 2000, resalta la participación privada y asigna un lugar primordial a la privatización del sector en un importante número de países de la región. Sin duda, este proceso ha sido relevante en países como la Argentina, el Brasil y Chile, pero en otros como Panamá y la República Bolivariana de Venezuela no ha tenido el efecto esperado. En cambio, países que conservaron la estructura original de su industria telefónica también han alcanzado niveles importantes de expansión de su conectividad telefónica, como Costa Rica y el Uruguay, no obstante que en otros países — que también optaron por mantener el monopolio estatal- se observa un significativo rezago (Rozas, 2005; Rozas, 2008a).

El trasfondo de la disminución de la brecha pareciera radicar en dos grupos de factores, los primeros vinculados a la profunda transformación productiva que experimentó la industria de las telecomunicaciones en el último decenio, y los segundos a las formas de organización de los mercados que fueron posibles luego de la transformación productiva de la actividad. La introducción de la fibra óptica — especialmente de la banda ancha- no solo abarató el costo de la transmisión de voces a niveles impensados en el período precedente; a ello agréguese que permitió la transmisión de imágenes y datos, lo que devino en la diversificación del negocio de la telefonía tradicional, que se extendió prontamente a la televisión pagada y la provisión de servicios de Internet, generando importantes economías de ámbito y nuevas fuentes de ingresos para las empresas operadoras de telefonía fija.

Además, se produjo la masificación de la telefonía móvil mediante la introducción del CPP (el que llama paga) y del prepago como modalidades de recaudación y de extensión del negocio. Los efectos provocados por estos elementos fueron, principalmente, una rápida erosión de las economías de escala y la aparición de nichos de 
mercado donde fue posible la participación simultánea de varios actores y la competencia, a veces descarnada, entre estos, lo que se tradujo en progresivos incrementos de los niveles de inversión en procura de penetrar y/o defender posiciones de mercado y de desarrollar nuevos productos. Todo ello condujo a ampliar y a diversificar la oferta de servicios de telecomunicaciones a niveles que autosustentaron su desarrollo, más allá del origen público o privado del capital de las empresas operadoras.

A diferencia de lo ocurrido en la industria de telecomunicaciones, el desarrollo de la infraestructura de transporte en América Latina, probablemente el área que más duramente resintió la disminución de la inversión entre 1980 y 2001, muestra un notorio rezago con respecto a otras economías emergentes, de acuerdo con la información disponible. Hacia 1980, la cantidad de kilómetros de carreteras pavimentadas por habitante en América Latina $(1,10)$ casi duplicaba la cifra mostrada por las economías del sudeste de Asia $(0,58)$; en cambio, en 2000 la situación se había revertido en favor de las economías asiáticas cuya cantidad de kilómetros de carreteras pavimentadas por habitante superaba en 50\% a la de las economías latinoamericanas. Peor aún: en América Latina la cantidad de kilómetros de carreteras pavimentadas por habitante disminuyó en términos absolutos, cayendo de 1,10 en 1980 a 0,86 en 2000 . En gran medida, esta última variación deja entrever que los países latinoamericanos no solo no crearon nueva infraestructura, sino que además no conservaron adecuadamente la existente durante el período analizado. Es posible que esta tendencia se haya acentuado durante el primer lustro de la década de 2000, debido a las dificultades de orden fiscal que surgieron en varios países de la región.

\section{Infraestructura de menor calidad}

Una de las consecuencias de la insuficiente inversión en infraestructura en los países de la región en las últimas dos o tres décadas se relaciona con la calidad de los servicios provistos, la que sería inferior a los estándares internacionales que prevalecen no solo en los países desarrollados, sino también en otras economías emergentes. Si bien es cierto que no se dispone de indicadores objetivos de esta variable — de por sí un aspecto complejo que contiene muchas aristas en cada una de las áreas de la infraestructura básica- es posible tener una idea aproximada a partir del ordenamiento de los países que elabora el Foro Económico Mundial en función de un índice global de la calidad de los servicios de infraestructura.
De acuerdo con este ordenamiento, los países del sudeste de Asia -incluso los de industrialización reciente- son percibidos en general con mejores índices de calidad que los países de América Latina. Los primeros se ubican entre los lugares 3 y 28 , con calificaciones que oscilan entre 6,6 y 5,1 puntos. En cambio, ningún país latinoamericano logra situarse entre los 28 países mejor calificados y sus resultados oscilan entre 1,9 y 5 , lo que determina su clasificación en lugares que van desde el 30 hasta el 129 (véase el cuadro 4).

El país latinoamericano mejor calificado es Chile (posición 30), cuyos servicios de infraestructura recibieron una calificación de 5 puntos, casi inmediatamente detrás de Tailandia, la economía asiática de industrialización reciente que recibió la menor calificación. Mucho más atrás le siguen el Uruguay y la Argentina (lugares 61 y 80 , respectivamente) con calificaciones respectivas de 3,7 y 3,1 puntos.

Esto determina una situación especialmente preocupante para los países de América Latina: la calidad de los servicios de infraestructura no solo es percibida como inferior con respecto a la de los países asiáticos, sino que además es mal calificada en términos absolutos, con la excepción de Chile.

En la información relativa a servicios específicos de infraestructura no cambia en demasía esta tendencia

CUADRO 4

Índice de calidad de la infraestructura en economías de Asia y de América Latina, 2007

\begin{tabular}{lcc}
\hline País & Calificación & $\begin{array}{c}\text { Puntaje } \\
\text { promedio }\end{array}$ \\
\hline Singapur & 3 & 6,6 \\
Hong Kong (Región Administrativa & & \\
Especial de China) & 8 & 6,2 \\
Malasia & 18 & 5,7 \\
República de Corea & 19 & 5,6 \\
Provincia china de Taiwán & 22 & 5,4 \\
Tailandia & 28 & 5,1 \\
Chile & 30 & 5,0 \\
Uruguay & 61 & 3,7 \\
Argentina & 80 & 3,1 \\
Colombia & 89 & 2,8 \\
Suriname & 91 & 2,8 \\
Ecuador & 92 & 2,8 \\
Brasil & 97 & 2,7 \\
Guyana & 100 & 2,7 \\
Perú & 104 & 2,5 \\
Venezuela (Rep. Bol. de) & 105 & 2,5 \\
Bolivia (Est. Plur. de) & 123 & 2,1 \\
Paraguay & 129 & 1,9 \\
\hline
\end{tabular}

Fuente: M. Porter, Klaus Schwab y X. Sala-i-Martin, The Global Competitiveness Report 2007-2008, Nueva York, Palgrave Macmillan, 2007. 
GRÁFICO 15

\section{Calidad de la infraestructura vial}

$(7=$ mejor $y 1=$ peor $)$

Calificación

Puntaje

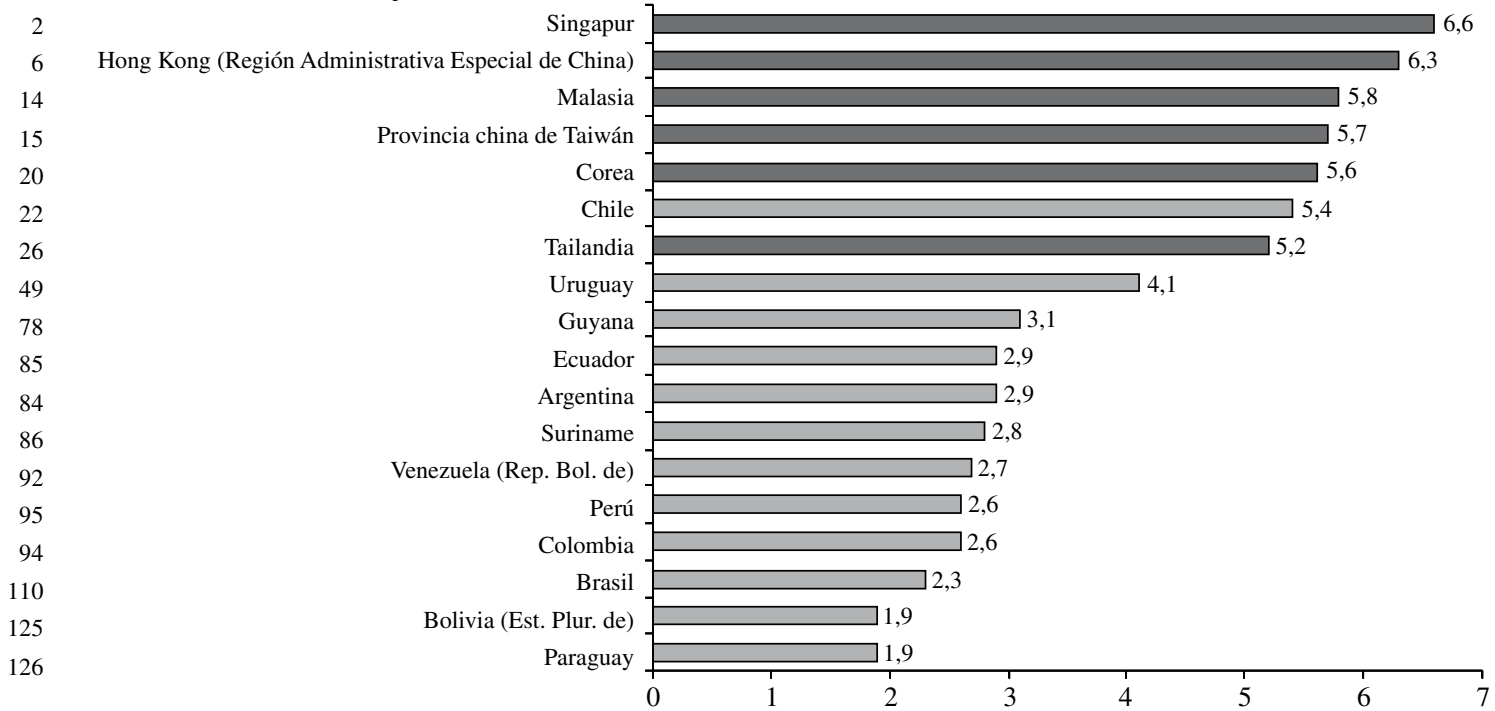

Fuente: M. Porter, Klaus Schwab y X. Sala-i-Martin, The Global Competitiveness Report 2007-2008, Nueva York, Palgrave Macmillan, 2007.

GRÁFICO 16

\section{Calidad de infraestructura ferroviaria}

$(7=$ mejor $y 1=$ peor $)$

Calificaci
2
6
14
15
20
22
26
49
78
85
84
86
92
95
94
110
125
126

Puntaje

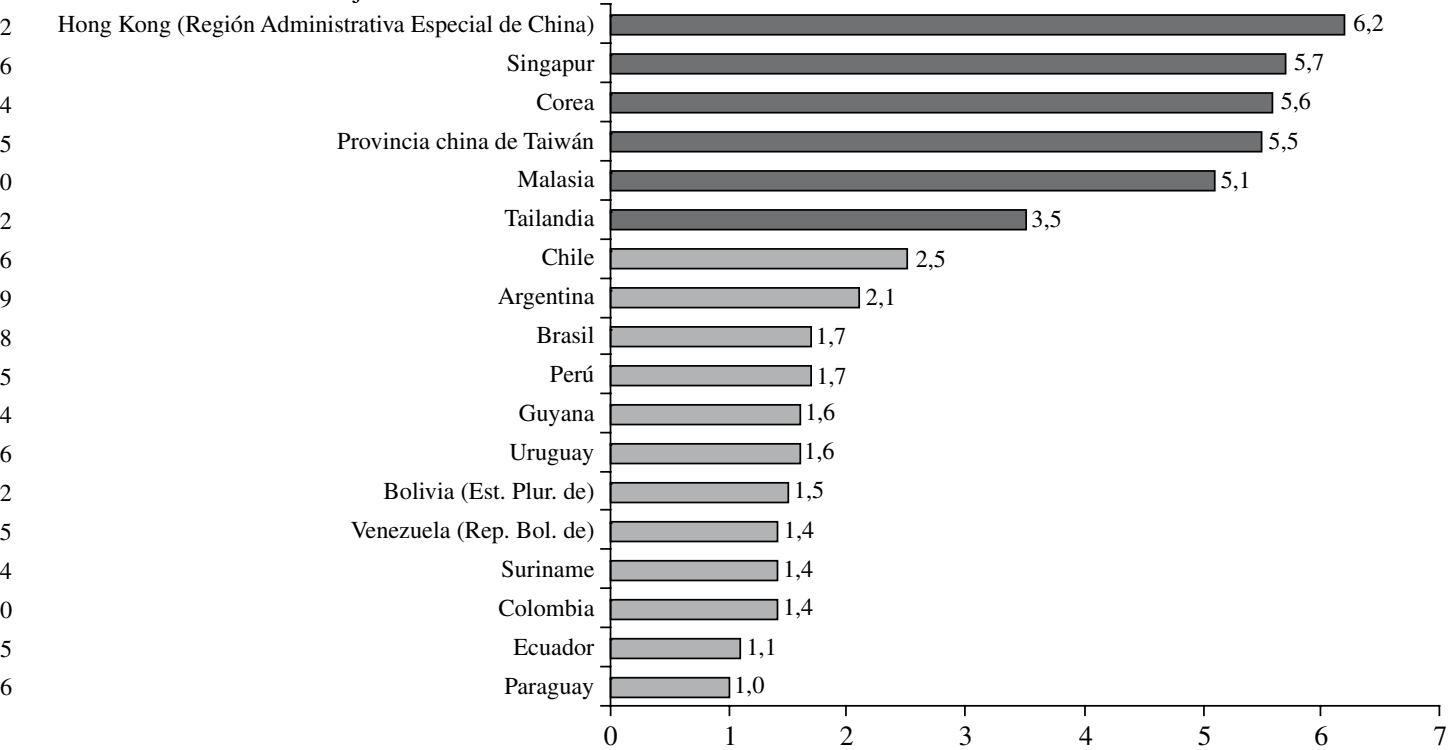

Fuente: M. Porter, Klaus Schwab y X. Sala-i-Martin, The Global Competitiveness Report 2007-2008, Nueva York, Palgrave Macmillan, 2007. 
GRÁFICO 17

\section{Calidad de infraestructura portuaria}

$(7=$ mejor $y$ l= peor $)$

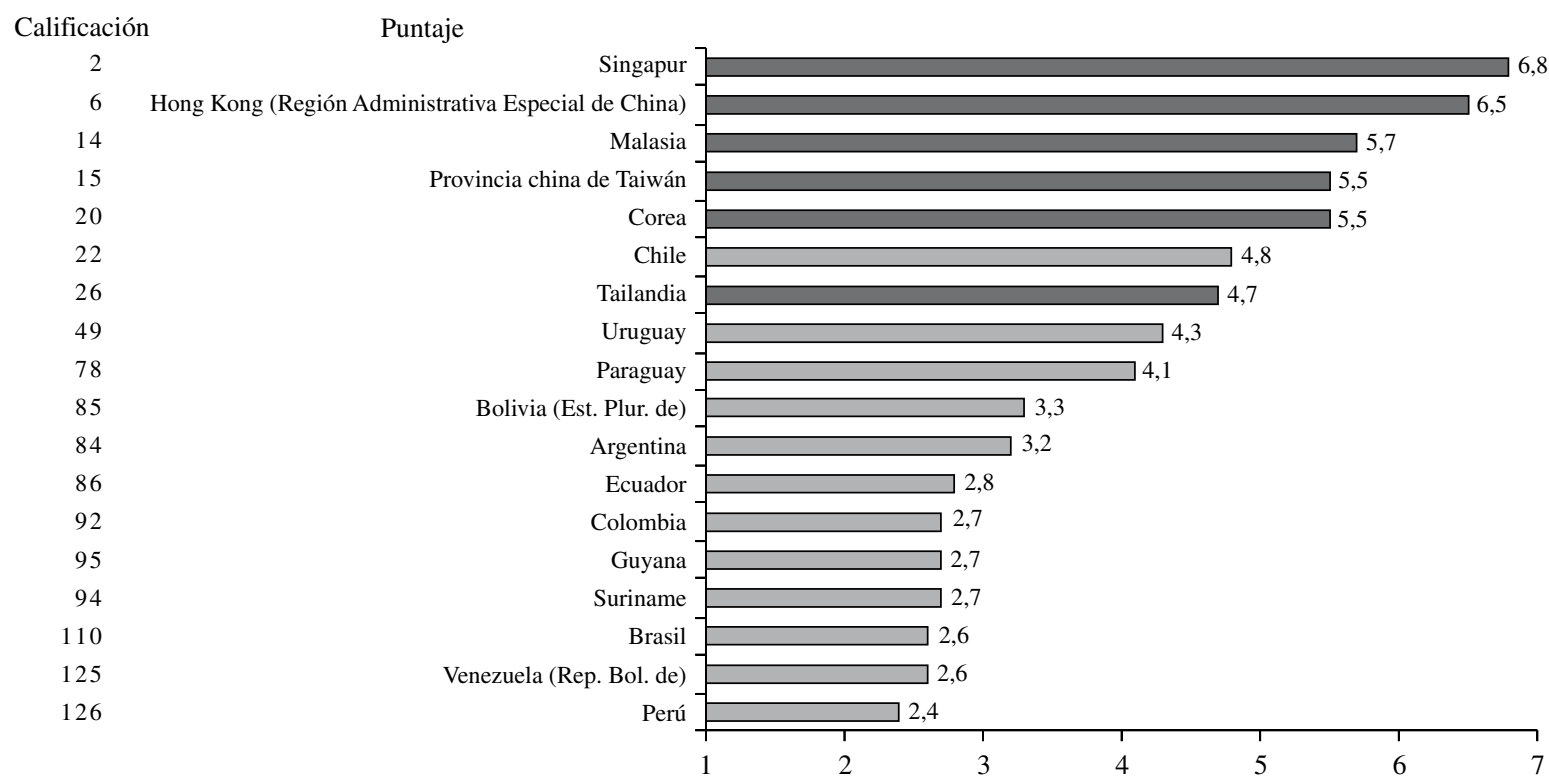

Fuente: M. Porter, Klaus Schwab y X. Sala-i-Martin, The Global Competitiveness Report 2007-2008, Nueva York, Palgrave Macmillan, 2007.

GRÁFICO 18

\section{Calidad de infraestructura de transporte aéreo}

$(7=$ mejor y $l=$ peor $)$

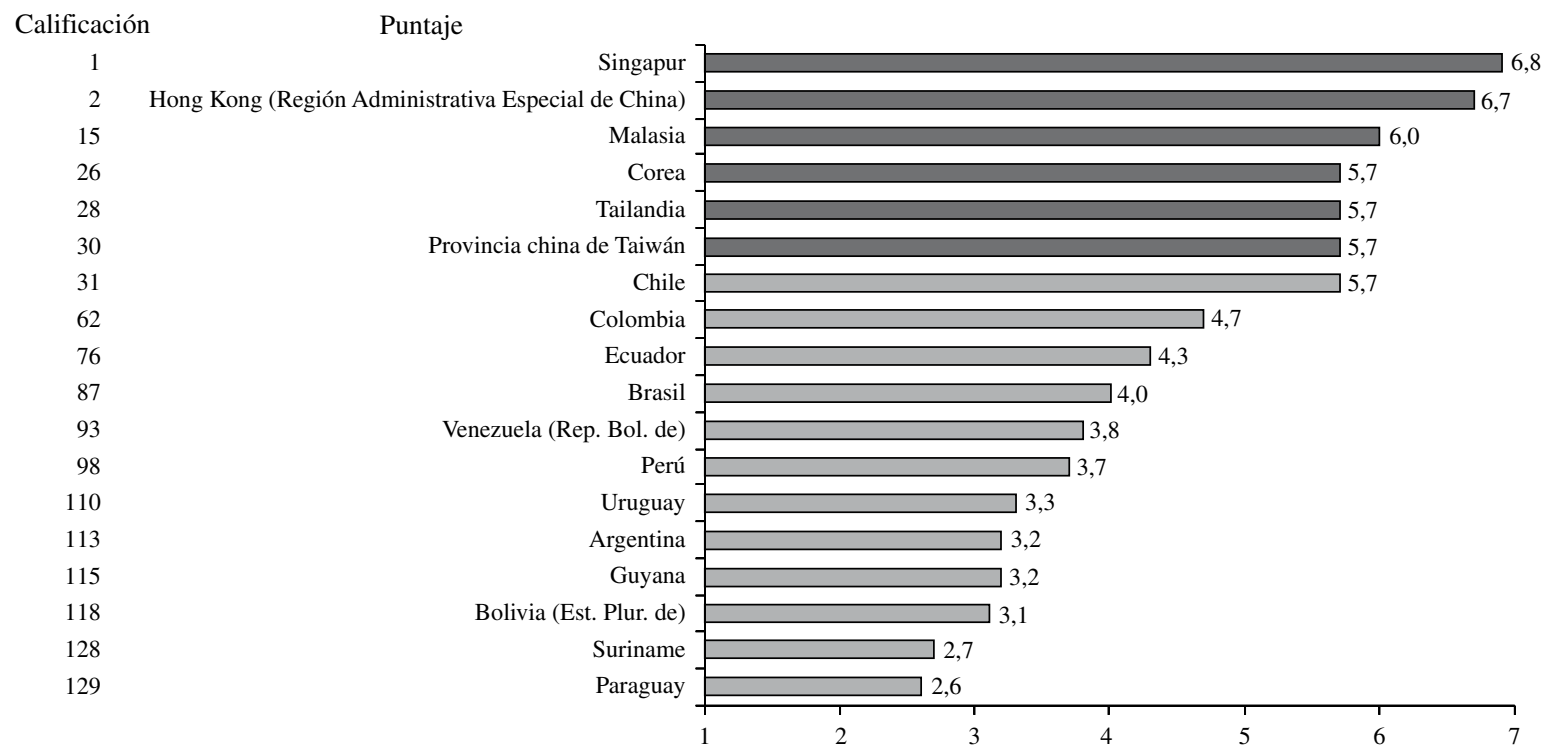

Fuente: M. Porter, Klaus Schwab y X. Sala-i-Martin, The Global Competitiveness Report 2007-2008, Nueva York, Palgrave Macmillan, 2007. 
GRÁFICO 19

\section{Calidad de infraestructura telefónica}

$(7=$ mejor $y 1=$ peor $)$

Calificación Puntaje

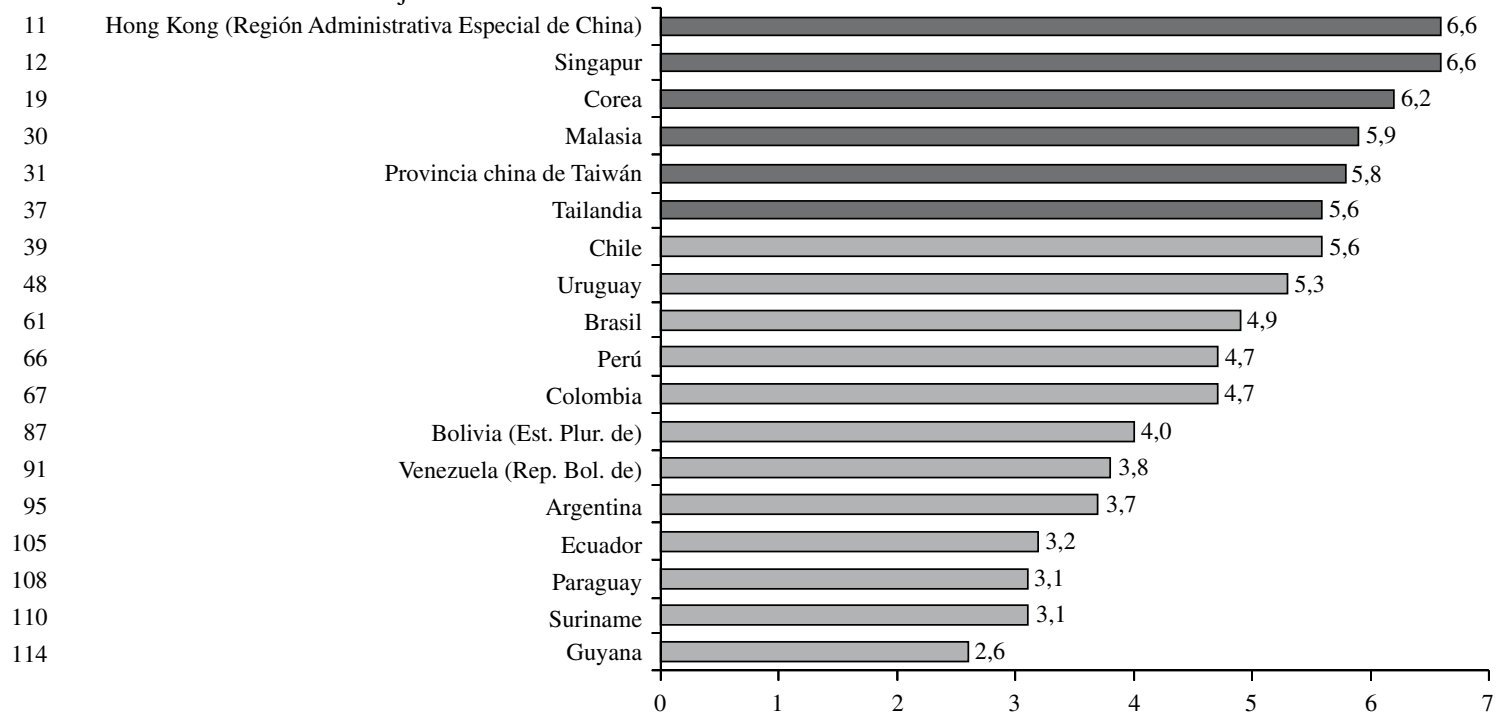

Fuente: M. Porter, Klaus Schwab y X. Sala-i-Martin, The Global Competitiveness Report 2007-2008, Nueva York, Palgrave Macmillan, 2007.

GRÁFICO 20

\section{Calidad del suministro eléctrico}

$(7=$ mejor $y 1=$ peor $)$

Calificación

Puntaje

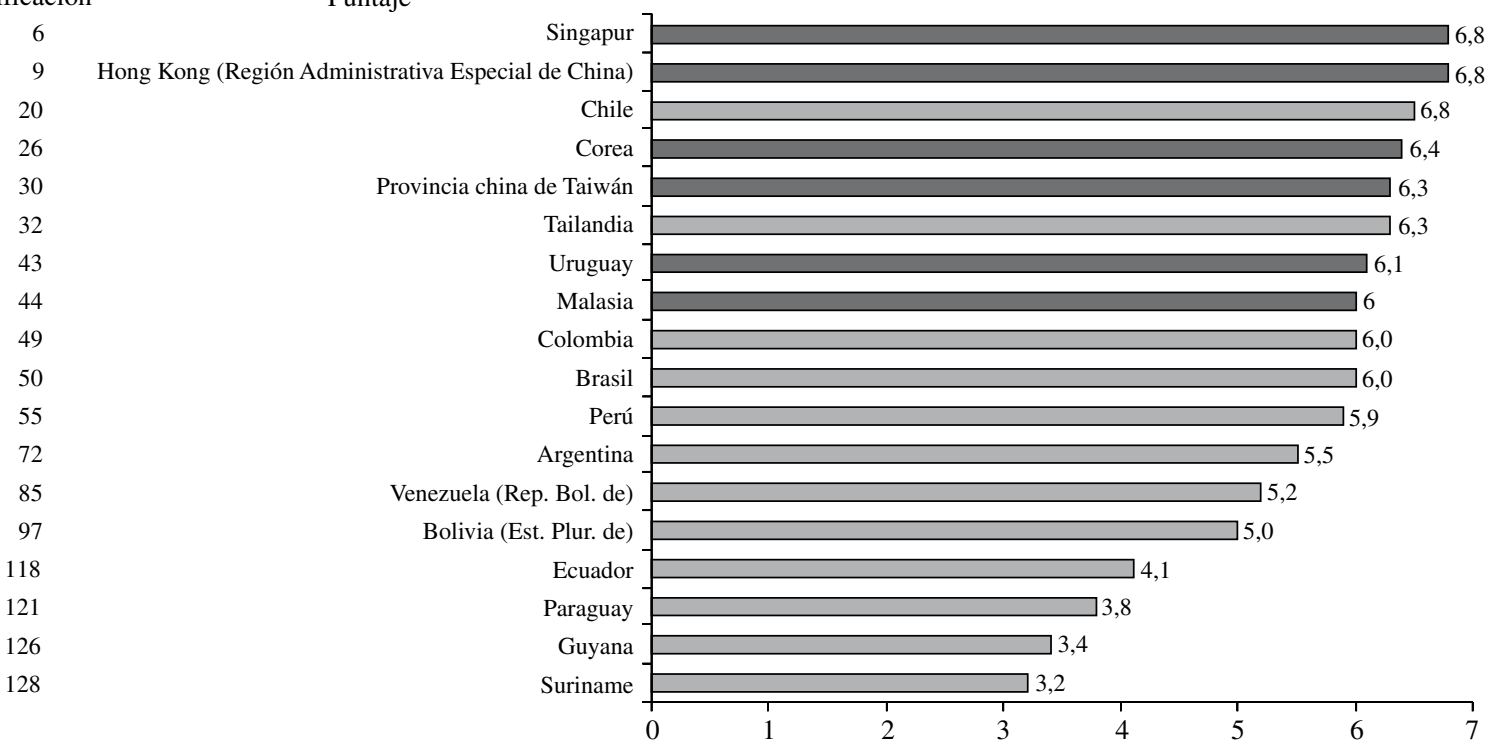

Fuente: M. Porter, Klaus Schwab y X. Sala-i-Martin, The Global Competitiveness Report 2007-2008, Nueva York, Palgrave Macmillan, 2007. 
general. Como se aprecia en los gráficos presentados en la página anterior, en infraestructura vial, ferroviaria, portuaria, de transporte aéreo y de telecomunicaciones los países del sudeste asiático de industrialización reciente presentan mejores índices de calidad que los países latinoamericanos. Excepcionalmente, Chile ha obtenido calificaciones superiores a algunos de los países del sudeste asiático en la prestación de servicios de infraestructura vial y portuaria (mejor que Tailandia). Asimismo, Chile supera a la República de Corea, Malasia, Tailandia y la provincia china de Taiwán en la calidad de la prestación de servicios eléctricos, lo que también logra parcialmente el Uruguay, que en esta área supera a Malasia y Tailandia.

En los gráficos expuestos en la página anterior se advierte, asimismo, que el mayor rezago de los países de la región latinoamericana se produce en la infraestructura ferroviaria, portuaria y vial, no así en la infraestructura eléctrica, en la que ocho países de la región (la Argentina, el Brasil, Chile, Colombia, el Estado Plurinacional de Bolivia, el Perú, el Uruguay y la República Bolivariana de Venezuela) obtienen calificaciones superiores a 5 puntos. Especialmente preocupante es la percepción de la calidad de la infraestructura ferroviaria, en la que el país latinoamericano mejor calificado es Chile, que obtuvo solo 2,5 puntos. También debe ser motivo de preocupación el área de infraestructura portuaria, en la que ningún país latinoamericano obtiene una calificación superior a 5 puntos. Asimismo, únicamente Chile obtiene una calificación sobre este nivel en la infraestructura vial. En definitiva, los países de la región latinoamericana muestran un claro rezago en la prestación de servicios en todas las áreas de infraestructura, con la excepción de la industria eléctrica, donde el rezago es bastante menor. Esta situación se extiende incluso a la industria de telecomunicaciones, la única que registra incrementos de la tasa de inversión, como se expuso anteriormente.

\section{IV}

\section{¿Cómo reducir la brecha de infraestructura?}

América Latina enfrenta con urgencia el desafío de reducir la brecha que hoy la distancia de las economías más dinámicas del sudeste de Asia en cuanto a disponibilidad y calidad de los servicios de infraestructura, para evitar con ello verse superada por la dinámica del crecimiento de otras economías asiáticas emergentes, ya poseedoras de ventajas competitivas, lo que podría desfavorecer las posibilidades de inserción de América Latina en el nuevo orden económico internacional.

La literatura especializada y los expertos coinciden en señalar que América Latina debe aumentar su inversión anual en infraestructura. Fay y Morrison (2005) estiman que si los países de la región invierten anualmente el $0,25 \%$ del PIB podrían alcanzar la cobertura universal en un plazo razonable tanto en electricidad como en aguas y saneamiento, debido a que ya disponen de un alto nivel de cobertura, con excepción del tratamiento de las aguas servidas que presenta un atraso considerable.

A su vez, estas mismas autoras señalan que un mantenimiento adecuado de los activos existentes en las áreas de agua potable, saneamiento, electricidad, caminos, ferrocarriles y telecomunicaciones requeriría un equivalente al $1 \%$ del PIB regional. Finalmente, Fay y Morrison estiman que se requiere un 1,3\% del PIB para solventar nuevas inversiones y atender satisfactoriamente la mayor demanda que es posible que se genere sobre la base de proyecciones conservadoras del crecimiento económico.

En definitiva, la región latinoamericana requiere invertir en infraestructura alrededor del 2,5\% del PIB para responder al crecimiento inercial de la demanda, pero un porcentaje del PIB un poco mayor (entre $4 \%$ y $6 \%$ ) para alcanzar los niveles actuales de las economías más dinámicas del sudeste asiático.

En diversos foros, especialistas del sector han señalado que los países de América Latina deberían plantearse como objetivo gastar anualmente en infraestructura montos equivalentes al $7 \%$ del PIB para una mantención adecuada de la infraestructura existente y reducir la brecha con los países desarrollados y las economías emergentes más pujantes del sudeste de Asia. Según el Banco Mundial, plantearse alcanzar un nivel de inversión en infraestructura equivalente al $7 \%$ del PIB no sería irrealista si se considera que ese fue el nivel de gasto que registraron países como China, Indonesia, República de Corea y Malasia entre 1970 y 1990, y que hoy muestran importantes niveles de desarrollo de su infraestructura. Incluso países como China han invertido en infraestructura en los años más recientes montos que equivalen al 9\% del PIB.

No obstante, debe tenerse presente que dicho objetivo no puede ser planteado de igual manera para todos 
los países de América Latina dada su heterogeneidad estructural y debido a las diferentes tasas de inversión en infraestructura que estos países han venido sosteniendo en los últimos años. Con seguridad, la repercusión en otras variables clave de la conducción económica será distinta en un país que aumente su tasa de inversión en infraestructura del $6 \%$ al $7 \%$ del PIB respecto de otro que la incremente de un $2,1 \%$ al $7 \%$.

Sin embargo, los tiempos apremian. A partir de 2003, América Latina ha registrado una importante expansión de su capacidad productiva, lo que se refleja en niveles de incremento del PIB que duplican la tasa promedio de crecimiento lograda entre 1980 y 2002 $(2,2 \%)$. Esto implica que la demanda por servicios de infraestructura también ha aumentado rápidamente por sobre el crecimiento inercial y continuará acrecentándose conforme se extienda el ciclo de expansión de la actividad económica en su conjunto. Dado el comportamiento de la inversión en el sector, es muy posible que se produzcan importantes desajustes en la oferta y demanda de estos servicios, en desmedro de las posibilidades de desarrollo de las demás actividades productivas.

América Latina no puede pasar por alto que la expansión de su capacidad productiva ha sido impulsada principalmente por factores externos vinculados a la globalización de la economía mundial y que se expresan en una creciente demanda de bienes transables, una mayor liquidez de los mercados financieros internacionales y la emergencia de importantes cambios en los patrones del comercio internacional y los términos de intercambio. Estos últimos han permitido a los países de América Latina diversificar las corrientes de comercio, incrementar el número de socios comerciales, engrosar sus exportaciones y obtener mejores precios por sus productos.

En consecuencia, la posibilidad de los países latinoamericanos de mantener este ciclo de expansión y crecimiento, así como de conservar su inserción en los mercados internacionales, está condicionada - entre otros factores - por una mejora sustantiva de su infraestructura básica, tanto en lo que se refiere a la cobertura y acceso a los servicios prestados, como a su calidad y precios.

El desafío de resolver el déficit de arrastre en el desarrollo de infraestructura y reducir las brechas que separan a América Latina de los países desarrollados y del grupo de países más dinámicos del sudeste asiático implica no solo aumentar la inversión pública en el sector, sino también realizar un esfuerzo considerable para atraer nueva inversión privada, que debiera orientarse sobre todo a incrementar el acervo de capital del sector y no a la mera transferencia de activos. Para ello resulta imprescindible ampliar y diversificar los esquemas de participación público-privada, y lograr un apoyo más decidido de los organismos multilaterales de crédito al desarrollo de la infraestructura en la región. En este sentido, dichos organismos deben revisar autocríticamente las políticas impulsadas en la última década y apoyar seriamente la creación de infraestructura en los países de la región.

En los antecedentes expuestos en páginas anteriores se delinea la envergadura de la tarea que los países latinoamericanos tienen por delante. Antes que nada, los gobiernos deben asumir que la tasa de inversión en infraestructura que hoy predomina en la región es claramente insuficiente, y que en el mejor de los casos solo permite la ejecución de tareas de conservación de la infraestructura existente.

Asimismo, los gobiernos de la región deben asumir que la inversión privada, en general, no ha logrado sustituir a la inversión pública ni transformarse en la base de sustentación financiera del desarrollo del sector, con excepción de la industria de telecomunicaciones en algunos de los países latinoamericanos, merced a las políticas de competencia y de organización industrial que se implementaron conjuntamente con la privatización de las empresas estatales que dominaban el mercado.

De hecho, en los antecedentes compilados es posible advertir que los países que registran un mayor rezago en la tasa de inversión en infraestructura respecto de los estándares internacionales son aquellos que aplicaron con mayor fidelidad las recomendaciones del denominado "Consenso de Washington" y que, en consecuencia, disminuyeron más drásticamente la inversión pública en el sector. En cambio, los países que lograron incrementar su tasa de inversión en infraestructura son aquellos que mantuvieron altos niveles de inversión pública y abrieron simultáneamente espacios a la inversión privada, señalando un camino heterodoxo respecto de dichas recomendaciones.

En relación con otras fases de expansión de la economía de América Latina, los países de la región están en una posición inmejorable para aumentar la inversión pública en infraestructura e impulsar un dinámico crecimiento del sector, dando cuenta del buen pie de las finanzas públicas y de los equilibrios de las cuentas macroeconómicas principales. En general, las economías latinoamericanas disponen hoy de mayores niveles de ahorro y de inversión que en las fases anteriores; además, sus finanzas públicas son más sanas y cuentan con importantes superávits en sus cuentas corrientes, a la vez que su vulnerabilidad externa ha disminuido considerablemente. Ello, nuevamente, coloca a los gobiernos de los países de la región en el centro de los desafíos que deben afrontarse para mejorar los servicios de infraestructura. 
Bibliografía

Andrés, Luis; Vivien Foster y José Luis Guasch (2006), "The impact of privatization on firms in the infrastructure sector: the case of electricity distribution in Latin American countries", Policy Research Working Paper, № 3936, Washington, D.C., Banco Mundial.

Bull, Alberto (2004), "Concesiones viales en América Latina: situación actual y perspectivas", serie Recursos naturales e infraestructura, $\mathrm{N}^{\circ} 79$ (LC/L.2207-P), Santiago de Chile, Comisión Económica para América Latina y el Caribe (CEPAL), octubre. Publicación de las Naciones Unidas, $\mathrm{N}^{\circ}$ de venta: S.04.II.G.131.

(2003), "Mejoramiento de la gestión vial con aportes específicos del sector privado", serie Recursos naturales e infraestructura, No 56 (LC/L.1924-P), Santiago de Chile, Comisión Económica para América Latina y el Caribe (CEPAL), junio. Publicación de las Naciones Unidas, $\mathrm{N}^{\circ}$ de venta: S.03.II.G.81.

Calderón, César y Luis Servén (2004), "Trends in infrastructure in Latin America, 1980-2001", Documento de trabajo, No 269 , Santiago de Chile, Banco Central de Chile, septiembre.

Canning, D. y P. Pedroni (1999), "The Contribution of Infrastructure to Aggregate Output”, Belfast, Reino Unido, Queen's University Belfast, inédito.

CEPAL (Comisión Económica para América Latina y el Caribe) (2004), Desarrollo productivo en economías abiertas (LC/G.2234(SES.30/3)), Santiago de Chile, junio.

Doerr, Octavio y Ricardo Sánchez (2006), "Indicadores de productividad para la industria portuaria. Aplicación en América Latina y el Caribe", serie Recursos naturales e infraestructura, $\mathrm{N}^{\circ} 112$ (LC/L.2578-P), Santiago de Chile, Comisión Económica para América Latina y el Caribe (CEPAL). Publicación de las Naciones Unidas, $\mathrm{N}^{\mathrm{o}}$ de venta: S.06.II.G.108.

Fay, Marianne y Mary Morrison (2005), Infrastructure in Latin America \& the Caribbean. Recent Developments and Key Challenges, Washington, D.C., Banco Mundial.

Foster, Vivien (2003), "Mirando hacia atrás: ¿qué funcionó y qué no funcionó en las PPP?" [en línea]http://www.alide.org.pe/download/ СEDOM/Infraestructura_AS2003/Asociacion\%20Publico\%20 Privada/45mirandoVivien\%20FosterBsAS.pdf

Guasch, J.L. y J. Kogan (2001), "Inventories in developing countries: levels and determinants. A red flag for competitiveness and growth", Policy Research Working Paper Series, N 2552, Washington, D.C., Banco Mundial.
Kogan, J. (2008), "Financiamiento de la infraestructura: principales desafíos de las alianzas público-privadas y de la regulación de los mercados", presentación en el Seminario internacional "Infraestructura 2020: avances, déficits y desafíos" (CEPAL, Santiago de Chile, 10 de noviembre de 2008).

Lora, Eduardo (2007), "Public investment in infrastructure in Latin America", RES Working Papers, $\mathrm{N}^{\circ}$ 4502, Washington, D.C., Banco Interamericano de Desarrollo (BID).

(2001), "Structural reforms in Latin America: what has been reformed and how to measure it", RES Working Papers, $\mathrm{N}^{\circ} 4287$, Washington, D.C., Banco Interamericano de Desarrollo.

Porter, M., Klaus Schwab y X. Sala-i-Martin (2007), The Global Competitiveness Report 2007-2008, Nueva York, Palgrave Macmillan.

Rozas, Patricio (2008a), "Panorama de las telecomunicaciones en América Latina, 2008", Santiago de Chile, Comisión Económica para América Latina y el Caribe (CEPAL), por aparecer.

(2008b), "La internacionalización de las empresas eléctricas en América Latina: el caso de ENDESA", serie Recursos naturales e infraestructura, $\mathrm{N}^{\circ} 133$ (LC/L.2885-P), Santiago de Chile, Comisión Económica para América Latina y el Caribe (CEPAL). Publicación de las Naciones Unidas, $\mathrm{N}^{\mathrm{o}}$ de venta: S.08.II.G.22.

(2005), "Privatización, reestructuración industrial y prácticas regulatorias en el sector telecomunicaciones", serie Recursos naturales e infraestructura, $\mathrm{N}^{\circ} 93$ (LC/L.2331-P), Santiago de Chile, Comisión Económica para América Latina y el Caribe (CEPAL). Publicación de las Naciones Unidas, $\mathrm{N}^{\mathbf{o}}$ de venta: S.05.II.G.82.

Rozas, Patricio y Ricardo Sánchez (2004), "Desarrollo de infraestructura y crecimiento económico: revisión conceptual", serie Recursos naturales e infraestructura, $\mathrm{N}^{\circ} 75$ (LC/L.2182-P), Santiago de Chile, Comisión Económica para América Latina y el Caribe (CEPAL). Publicación de las Naciones Unidas, $\mathrm{N}^{\circ}$ de venta: S.04.II.G.109.

Sánchez, Ricardo y Gordon Wilmsmeier (2005), "Provisión de infraestructura de transporte en América Latina. Experiencia reciente y problemas observados", serie Recursos naturales e infraestructura, N $^{\circ} 94$ (LC/L.2360-P), Santiago de Chile, Comisión Económica para América Latina y el Caribe (CEPAL), agosto. Publicación de las Naciones Unidas, $\mathrm{N}^{\circ}$ de venta: S.05.II.G.86.

Vellutini, Roberto (2007), "Financiamento a infraestructura e parceiras público-privadas no setor de energia", Río de Janeiro. 